\title{
Twists and Turns of Platinum-Allene Complexes: NMR Techniques for the Study of the Dynamic Behavior in Solution
}

\author{
M. Teresa Quirós, ${ }^{\dagger, \|}$ María Paz Muñoz, ${ }^{*}, \dagger, \| \odot$ Jeppe Christensen, ${ }^{\ddagger, \S}$ and Simon J. Coles ${ }^{\ddagger}$ \\ ${ }^{\dagger}$ School of Chemistry, University of East Anglia, Earlham Road, NR4 7TJ, Norwich, U.K. \\ ${ }^{\ddagger}$ UK National Crystallography Service, Chemistry, University of Southampton, Highfield Campus, Southampton, SO17 1BJ, U.K. \\ ${ }^{\S}$ Diamond Light Source, Harwell Science and Innovation Campus, Oxfordshire OX11 ODE, U.K.
}

Supporting Information

ABSTRACT: Classic (dynamic exchange line-shape analysis) and novel (SSTD NMR) NMR techniques have been applied in order to obtain the kinetic and thermodynamic parameters of the three main processes occurring in the fluxional behavior of Pt-allene complexes with $\mathrm{N}$-containing ligands, in four and five coordination mode, in solution. Our results show intramolecular helical and rotational movements closely related to each other, confirming $\eta^{1}$-staggered structures as possible intermediates. The ligand exchange in these complexes seems to occur via a ligand-independent dissociative mechanism, where coordinating solvents might be involved in the stabilization of the intermediates. The differences observed in the interaction of allenes with other metals could be the basis to explain the divergent reactivity observed in platinum-catalyzed processes.

\section{INTRODUCTION}

The mode of coordination in metal-allene complexes is crucial for the understanding of the reactivity of these important systems. ${ }^{1} \eta^{2}$-Coordination of the metal with one of the double bonds is commonly proposed as the ground state (Scheme 1),

\section{Scheme 1. Metal-Allene Coordination Modes}

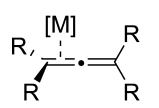

$\eta^{2}$-metal allene
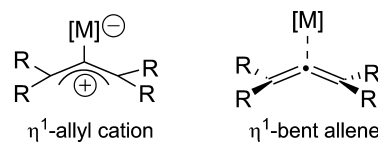

with different slippage structures toward the central or terminal carbons involved depending on the metal, the ligands, and the substitution on the allenes. More recently, $\eta^{1}$-metal-allene complexes have been proposed as high energy intermediates or transition states in metal-catalyzed reactions involving allenes. ${ }^{2}$ In this mode, the metal coordinates exclusively to the central carbon of the allene, and several structures have been proposed, detected, and even isolated: zwitterionic carbene, $\sigma$-allyl cation, or $\eta^{1}$-bent allenes (Scheme 1). Although a lot of attention has been paid to Au-allene complexes, ${ }^{3}$ studies on Pt-allene complexes are still rare.

Although platinum exhibits similar reactivity to gold in general, there are increasing examples where, under similar conditions, these two metals get involved in different reaction pathways and give different products. ${ }^{4}$ For example, we have reported the Pt-catalyzed dihydroalkoxylation and bisindolyla- tion of allenes, ${ }^{5}$ which give acetals or bisindolyl alkanes with double addition of the nucleophile to the terminal or less substituted double bond of the allene, and complete saturation of the second double bond, instead of the most common allyl derivatives obtained under gold catalysis. ${ }^{6}$ To explain the different reactivity of the two metals, different mechanisms and metallic intermediates have to be proposed for the two processes.

As part of our mechanistic studies on these reactions, we sought to gather experimental evidence on the type of coordination of the platinum and the allenes, in order to understand the subtle differences in reactivities observed in platinum catalysis, and to ascertain the involvement of $\eta^{1}$ coordinated allene complexes as reactive species in our catalytic cycle. As the isolation and analysis of $\mathrm{PtCl}_{2}$-allene complexes without stabilizing ligands is very challenging, for this study, we have selected a family of Pt-allene complexes with ancillary nitrogen-containing ligands in a four- or five-coordinated arrangement, ${ }^{8,9}$ active catalysts in our dihydroalkoxylation reaction, ${ }^{10}$ and we have studied them in solid state and in solution using different NMR techniques, including our recently reported SSTD NMR method. ${ }^{11}$

Three processes are proposed for the behavior of metalallene complexes in solution: the ligand exchange, the rotational movement ( $\pi$-face exchange, rotation of the metal around the allene), and the helical movement (the movement of the metal

Received: October 10, 2016 
from one double bond to another, Scheme 2). The mechanism of the last two processes can go via inter- or intramolecular

Scheme 2. Proposed Fluxional Pathways in Solution for PtAllene Complexes

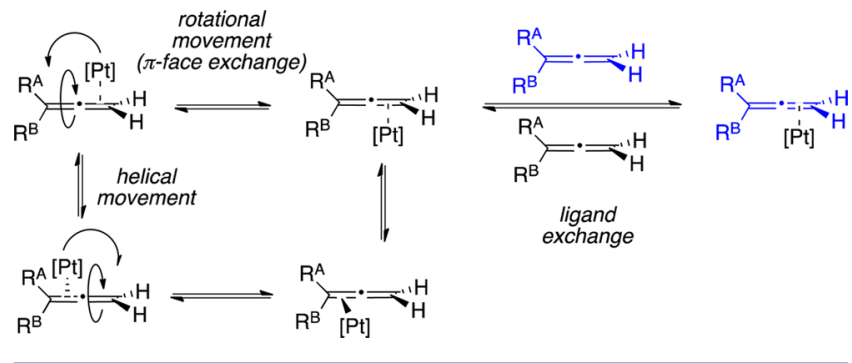

pathways, ${ }^{12}$ with important implications in catalysis and enantioselective processes involving chirality transfer from the allenes. ${ }^{13}$ Interestingly, despite the suggested disparity between the ground state and the reactive forms of Pt-allene complexes, experimental data regarding their behavior in solid state and solution are still lacking.

We encountered that classic VT experiments and line-shape analysis techniques, commonly used in the analysis of fluxional processes of organometallic complexes in solution, were not suitable to study some of our complexes due to thermal instability and higher coalescence temperatures than the decomposition temperatures. Therefore, a new method was developed and applied to these challenging systems, the SSTD (Spin Saturation Transfer Difference) NMR method. ${ }^{11}$ This new NMR protocol combines the Spin Saturation Transfer (SST) method used for small molecules, ${ }^{14}$ with the Saturation Transfer Difference (STD) NMR method employed for the study of protein-ligand interactions, ${ }^{15}$ by measuring transient spin saturation transfer along increasing saturation times (buildup curves) in systems undergoing mutual-site exchange. The method uses difference spectroscopy, based on the spin saturation transfer experiment, but avoiding the need to ensure steady state conditions and the determination of $T_{1}$ values. The transient spin saturation transfer is measured as the difference between the normal ${ }^{1} \mathrm{H}$ NMR spectrum and the ${ }^{1} \mathrm{H}$ NMR spectrum after saturation of one of the sites undergoing chemical exchange. We defined the $\eta_{\text {SSTD }}$ (spin saturation transfer difference parameter) as the measurement of the intensity of the "difference spectrum" (equilibrium-saturated, $M_{0 \mathrm{~A}}-M_{\mathrm{A}}$ ) over the intensity of the equilibrium spectrum $\left(M_{0 \mathrm{~A}}\right), \quad \eta_{\mathrm{SSTD}}=\left(M_{0 \mathrm{~A}}-M_{\mathrm{A}}\right) / M_{0 \mathrm{~A}} \cdot{ }^{9}$ This method was successfully applied in the most challenging cases to study the $\pi$-face exchange, as coalescence of the signals is not needed, so a more flexible temperature range can be used in the study. Further advantages of the method include: signal overlap does not interfere; there is no need to measure $T_{1}$ or reach steady state saturation; rate constant values are measured directly and $T_{1}$ values are obtained in the same experiment using only one set of experiments; and in contrast to line-shape analysis, the methodology is appropriate for low and high magnetic fields. We have also applied the method for the first time to the study of the ligand exchange process, showing the potential for further application of this methodology to the study of ligand exchange processes in other organometallic systems.

\section{RESULTS AND DISCUSSION}

Synthesis of the Pt-Allene Complexes. The synthesis of the $\mathrm{N}$-ligand- $\mathrm{PtCl}_{2}$-allene complexes was carried out by ligand exchange with the corresponding ethylene analogue, synthesized from the Zeise's salt and the corresponding ligand in good yields. ${ }^{16}$ The $\mathrm{Pt}(\mathrm{II})$-allene bond in the pyridine complexes has been shown to be stronger than the Pt-ethylene bond due to the relief of strain in the allene system upon coordination, ${ }^{16 a}$ with the release of ethylene gas as the driving force of the reaction.

Analysis of the complexes in solution by ${ }^{1} \mathrm{H}$ NMR and solid state by X-ray crystallography showed in all cases $\eta^{2}$ coordination in the ground state, with the platinum coordinated to the less substituted double bond in the complexes with mono- and 1,1-disubstituted allenes. This was supported by a clear shift of the protons in the terminal double bond to lower chemical shift in the ${ }^{1} \mathrm{H}$ NMR spectra, as reported for other metal-allene complexes. ${ }^{2}$ Interestingly, five-coordinated complexes 3 and 4 showed an upfield shift (>1 ppm) compared with four-coordinated complexes $\mathbf{1}$ and $\mathbf{2}$, and larger $J_{(\mathrm{Pt}-\mathrm{H})}$,

Scheme 3. Synthesis of N-Ligand-Pt-Allene Complexes

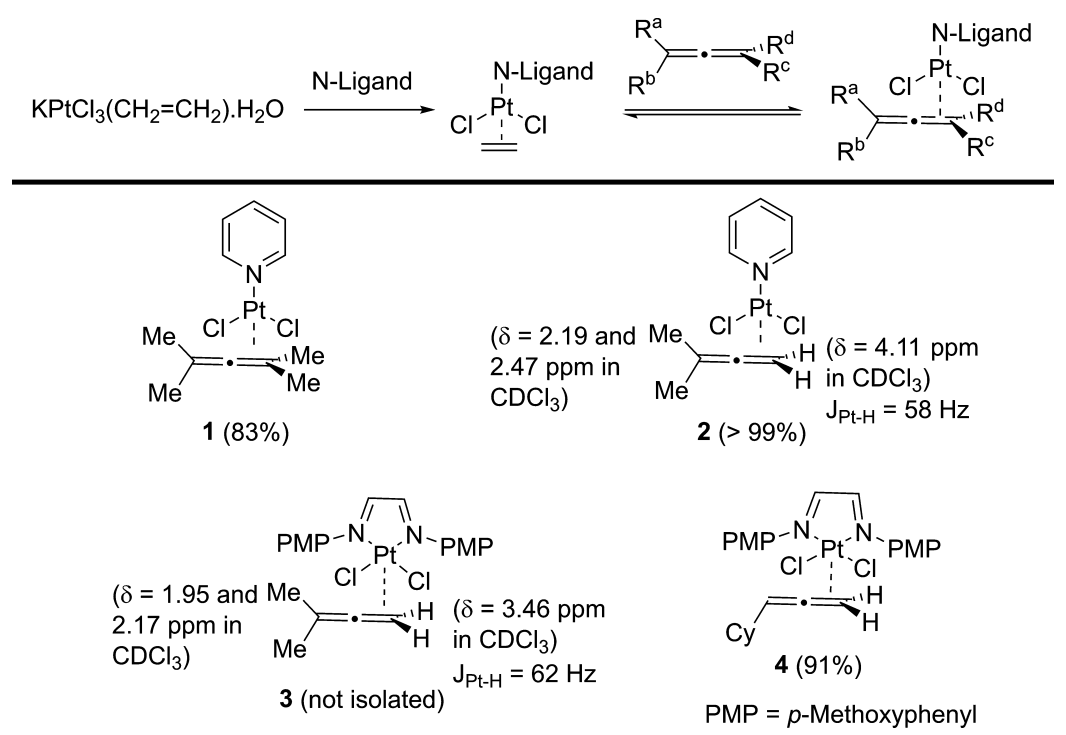


which supports the trigonal bypiramidal structure in these complexes (Scheme 3). This trend is also observed in the precursor ethylene complexes (see the SI for details), and it is in accordance with previous data reported for five-coordinated Pt-olefin complexes. ${ }^{17,18}$

Complexes 1 and $\mathbf{2}$ had been synthesized before, ${ }^{19}$ but to the best of our knowledge, no crystal structure of the complexes has been reported to date. We were able to obtain crystals of the two pyridine-complexes ( 1 and 2 ) by slow diffusion of EtOAc into a petroleum ether solution. ${ }^{20}$ The crystal structure of both compounds showed slipped $\eta^{2}$-coordination with a clear deviation from linearity in the $\mathrm{C}=\mathrm{C}=\mathrm{C}$ bond $\left(159.7(5)^{\circ}\right.$ in $2,153.7(3)^{\circ}$ in 1$),^{21}$ elongation of the $\mathrm{C}=\mathrm{C}$ bond coordinated to the platinum $(1.382(8) \AA$ (coordinated) vs 1.293(8) Å (noncoordinated) in 2, 1.371(4) Åv 1.304(4) Å in 1 ), and distorted linear conformation $\left(\mathrm{Pt}-\mathrm{C}^{1}-\mathrm{C}^{2}\right.$ (central) $72.2(3)^{\circ}$ in $2,36.43(12)^{\circ}$ in $\left.\mathbf{1}\right)$ with a clearly different distance of the platinum to the central and terminal carbons of the coordinated double bond, which is in accordance with other reported metal-allene complexes ${ }^{2}$ (Figures 1 and 2; see the SI

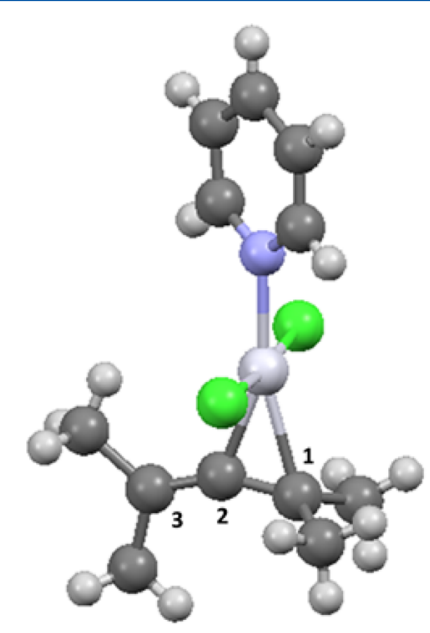

$C^{1}=C^{2}=C^{3}: 153.7^{\circ}$
$P t-C^{1}=C^{2}: 36.43^{\circ}$
$d\left(C^{1}=C^{2}\right): 1.371 \AA$
$d\left(C^{2}=C^{3}\right): 1.304 \AA$
$d\left(P t-C^{2}\right): 2.071 \AA$
$d\left(P t-C^{1}\right): 2.252 \AA$

Figure 1. Ball-and-stick representation of the crystal structure of Pyridine- $\mathrm{PtCl}_{2}$-TMA complex $\mathbf{1}$.

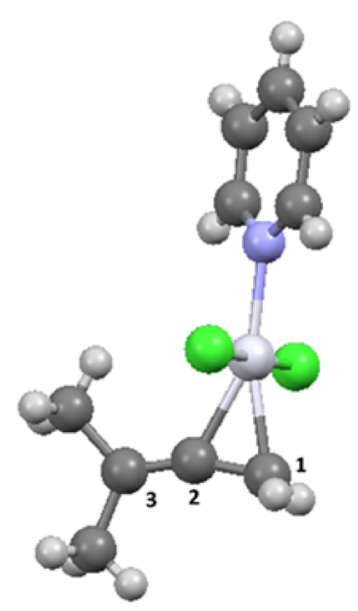

$\mathrm{C}^{1}=\mathrm{C}^{2}=\mathrm{C}^{3}: 159.7^{\circ}$

Pt $-C^{1}=C^{2}: 72.2^{\circ}$

$\mathrm{d}\left(\mathrm{C}^{1}=\mathrm{C}^{2}\right): 1.382 \AA$

$\mathrm{d}\left(\mathrm{C}^{2}=\mathrm{C}^{3}\right): 1.293 \AA$

$\mathrm{d}\left(\mathrm{Pt}-\mathrm{C}^{2}\right): 2.108 \AA$

$\mathrm{d}\left(\mathrm{Pt}-\mathrm{C}^{1}\right): 2.138 \AA$

Figure 2. Ball-and-stick representation of the crystal structure of Pyridine- $\mathrm{PtCl}_{2}$-DMA complex 2.

for full details). The distorted conformation is more pronounced in the TMA (tetramethyl allene) complex $\mathbf{1}$ with a distance of the platinum to the central carbon much shorter than to the terminal carbon and also shorter than in the 1,1 DMA (dimethyl allene) complex $\left(\mathrm{Pt}-\mathrm{C}_{(\text {central })}=2.071(3) \AA\right.$ in 1, 2.108(5) $\AA$ in 2; $\mathrm{Pt}-\mathrm{C}_{(\text {terminal })}=2.252(3) \AA$ in $1,2.138(6) \AA$ in 2), which resembles the $\eta^{1}$-staggered structures proposed in similar metal-allene complexes and suggested as reactive intermediates or transition states in platinum-catalyzed transformations. $^{22}$ The observed asymmetric binding has been previously attributed to backbonding interactions between the platinum and the $\pi^{*}$ orbital of the noncoordinated double bond that strengthens the platinum $-\mathrm{C}_{(\text {central })}$ bond, and causes the bending. ${ }^{23}$

Complexes 3 and 4 present a five-coordinated platinum(II), which is viable thanks to the fluxional behavior of the bidentate nitrogen ligand $(\mathrm{DAD}=\mathrm{PMP}-\mathrm{N}=\mathrm{CH}-\mathrm{CH}=\mathrm{N}-\mathrm{PMP}=$ diazadiene, Scheme 4). ${ }^{24}$ This has been previously studied in

Scheme 4. Fluxional Behaviour of the Nitrogen Ligand in the (DAD)-Pt-Allene Complexes

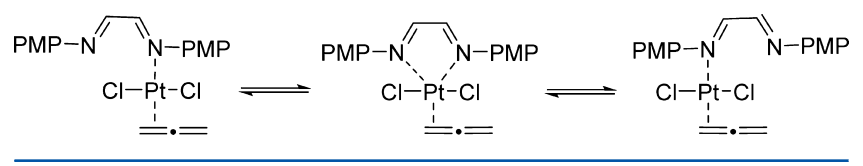

(DAD)-Pt-olefin complexes, ${ }^{16}$ and although we observed similar behavior in our experiments (see the SI for VT experiments showing the coalescence temperature), the details are not included here, as we were more interested in the fluxional behavior of the allene ligand.

The stability of the five-coordinated complex (DAD) $\mathrm{PtCl}_{2}$ (DMA) 3 in solution was poor, which made its isolation difficult. Therefore, this complex was characterized and used in situ once the ethylene gas had been completely excluded from the reaction mixture. Complex 4, however, was more stable and could be isolated in good yield.

During the synthesis of the (DAD)- $\mathrm{PtCl}_{2}$-allene complexes, we observed that complexation of the allene and displacement of the ethylene ligand were dependent on the solvent used. Moreover, we observed some dissociation of the allene in complex 4 depending on the solvent used to record the ${ }^{1} \mathrm{H}$ NMR spectra, in samples prepared from the isolated Pt-allene complexes. More interestingly, we observed that, excluding the chloroform, there was very good linear correlation between the ratio of free to coordinated allene $\left(K_{\mathrm{eq}}\right.$ in THF < Acetone < $\mathrm{CH}_{3} \mathrm{CN}$ ) with several solvent parameters (Figure 3; see the SI for full details). For example, $K_{\text {eq }}$ decreases with higher dipole moment, donicity (DN), and surface tension (solvent parameter values for THF $>$ Acetone $>\mathrm{CH}_{3} \mathrm{CN}$ ) and increases with increasing dielectric constant, solvent polarity, or acceptor number (AN) (solvent parameter values for THF < Acetone < $\mathrm{CH}_{3} \mathrm{CN}$ ). The best solvent to avoid dissociation of the allene seemed to be THF, with a high dipole moment, high donicity $(\mathrm{DN}=20){ }^{25}$ and low dielectric constant. The outliner behavior of the system in chloroform could be explained by the acidity and lack of coordinating ability of this solvent (DN is considered 0 for chlorohydrocarbons), which does not offer stabilization of the complex in solution and promotes decoordination and decomposition in the five-coordinated series.

These observations suggest ligand exchange processes and dynamic behavior in solution of these complexes, which is in agreement with previous reports in other metal-allene complexes fluxional behavior. ${ }^{26}$ 


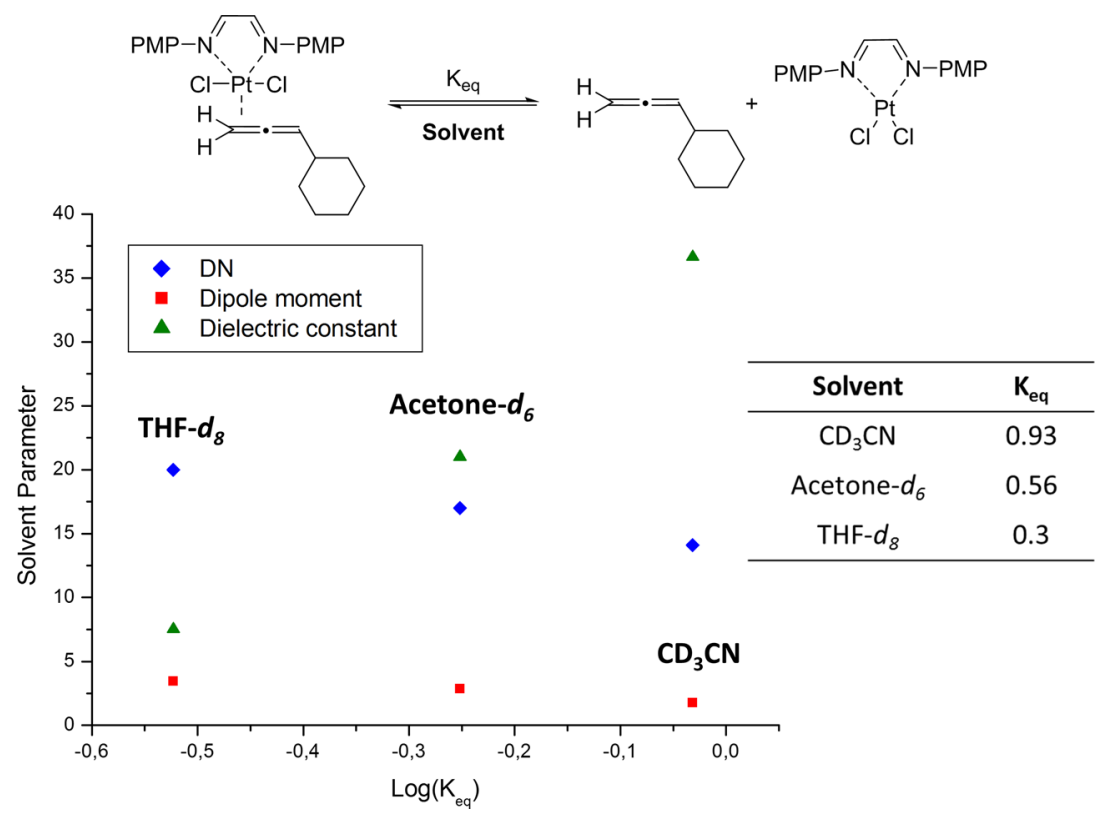

Figure 3. Dissociation of the allene in complex 4 in different solvents and correlation of $K_{\mathrm{eq}}$ with solvent parameters: DN (kcal mol ${ }^{-1}$, blue diamonds); dielectric constant ( $\varepsilon$, green triangles); dipole moment $\mu$ (Debyes, red squares).

In order to clarify the role of slipped $\eta^{2}$-complexes, $\eta^{1}$ coordinated species as intermediates or transition states, and the ligand exchange in our platinum-catalyzed transformations, we analyzed the three different processes of fluxional behavior (Scheme 2) of the complexes in Scheme 3 in solution, by using a combination of classic and new NMR techniques.

Helical Movement and $\boldsymbol{\pi}$-Face Exchange. Some data have been already reported in the study of fluxional behavior in $\mathrm{Pt}(\mathrm{II})$ - and $\mathrm{Pt}(0)$-allene complexes using line-shape analysis and SST NMR techniques. The helical movement or 1,2-metal shift has been studied in Pt-cyclic allene complexes (where the rotational movement is not possible due to the rigidity of the system) by Jones et al. using magnetization transfer experiments. ${ }^{27}$ They showed that a cationic Pt(II)-cycloheptatrienylidene complex exists preferably as the $\eta^{1}$-carbene tropylium ion form in solution, or as a very fast equilibrium between the $\eta^{2}$ Pt-allene structures (Scheme 5). However, the $\mathrm{Pt}(0)$-cycloheptatrienylidene complex exists only in the $\eta^{2}$-form and the helical movement was shown to be intramolecular (possibly via a carbene type intermediate, similar to the carbene tropylium) with a superimposed intermolecular component at higher temperatures.

Scheme 5. Helical Movement in Pt-Cyclic Allenes as Reported by Jones et al. ${ }^{27}$

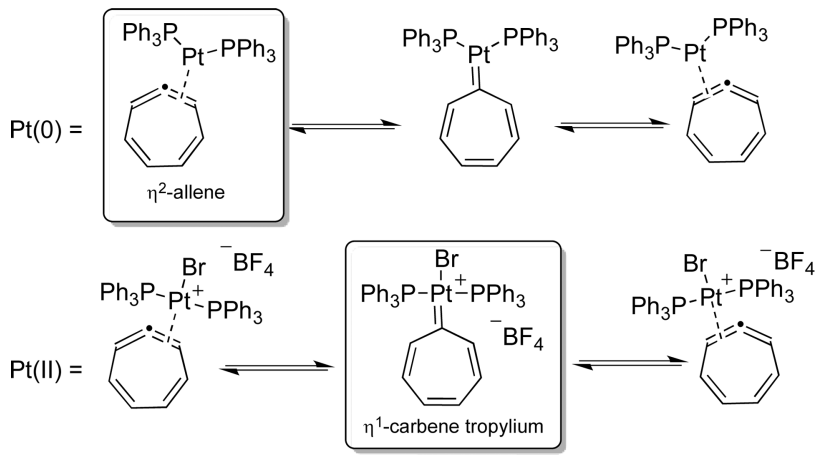

Previous studies of $\mathrm{Py}-\mathrm{Pt}(\mathrm{II})$-allene complexes of type $\mathbf{1}$ have shown that the fluxional movement is mononuclear with the ${ }^{195} \mathrm{Pt}-\mathrm{CH}_{3}$ coupling retained while the rate is independent of the concentration of complex. ${ }^{19,28}$ Besides, the influence of different substituted pyridine ligands showed that the rate of migration decreases with the increase basicity of the pyridines, which is in accordance with the increase in the strength of the Pt-allene $\pi$-bond with the $\sigma$-donor capacity of the ligands. Data for complex 1 with the unsubstituted pyridine showed a rate constant for the fluxional behavior of $k=30 \mathrm{~s}^{-1}$ at $-46{ }^{\circ} \mathrm{C}$ in $\mathrm{CDCl}_{3}{ }^{19 \mathrm{~b}}$ This rate was attributed to the helical movement (the $\mathrm{Pt}$ moves across the central carbon atom from one double bond to the other, which orbitals are orthogonal to each other), but the combination with the rotational movement was not analyzed in detail in this complex. In those studies, the rotational movement was suggested for the analogous complex with the DMA (2), to explain the same observed chemical shift, even at low temperatures, of the two terminal protons of the coordinated allene.

In order to obtain more information and all the thermodynamic parameters for the helical process, in which the platinum migrates between the allene double bonds, and to compare it with the rotational movement of the platinum around the allene axis, we analyzed complex 1 by dynamic exchange line-shape analysis using the DNMR module of TopSpin 3.0 (Bruker). ${ }^{29}$ This software simulates temperaturedependent experimental spectra, interactively set up according to a number of parameters (e.g., chemical shifts, intensity, line broadening, or rate constants) which can be fixed or allowed to vary, and iteratively refines the model parameters to get the best fit of the measured and simulated 1D NMR spectra to extract exchange rates. Although the kinetic data obtained are less precise than those obtained using classic line-shape analysis, coalescence of the signals is not needed, which was key in our complexes.

${ }^{1} \mathrm{H}$ NMR spectra of the complex at different temperatures were used for the fitting in the DNMR module of the TopSpin. The ${ }^{1} \mathrm{H}$ NMR of complex $\mathbf{1}$ at room temperature in deuterated 


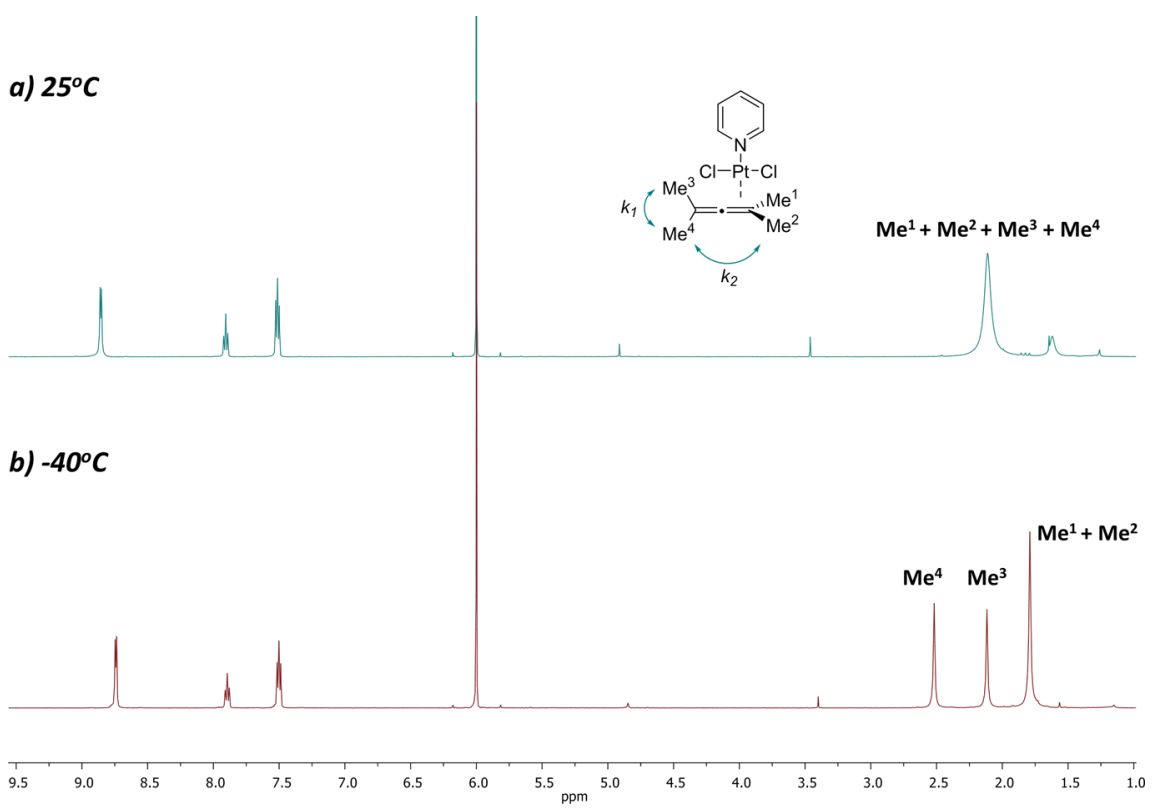

Figure 4. ${ }^{1} \mathrm{H}$ NMR of (Py) $\mathrm{PtCl}_{2}$ (TMA) 1 at $25{ }^{\circ} \mathrm{C}$ (a) and $-40{ }^{\circ} \mathrm{C}(\mathrm{b})$ in 1,1,2,2-tetrachloroethane- $d_{2}$.

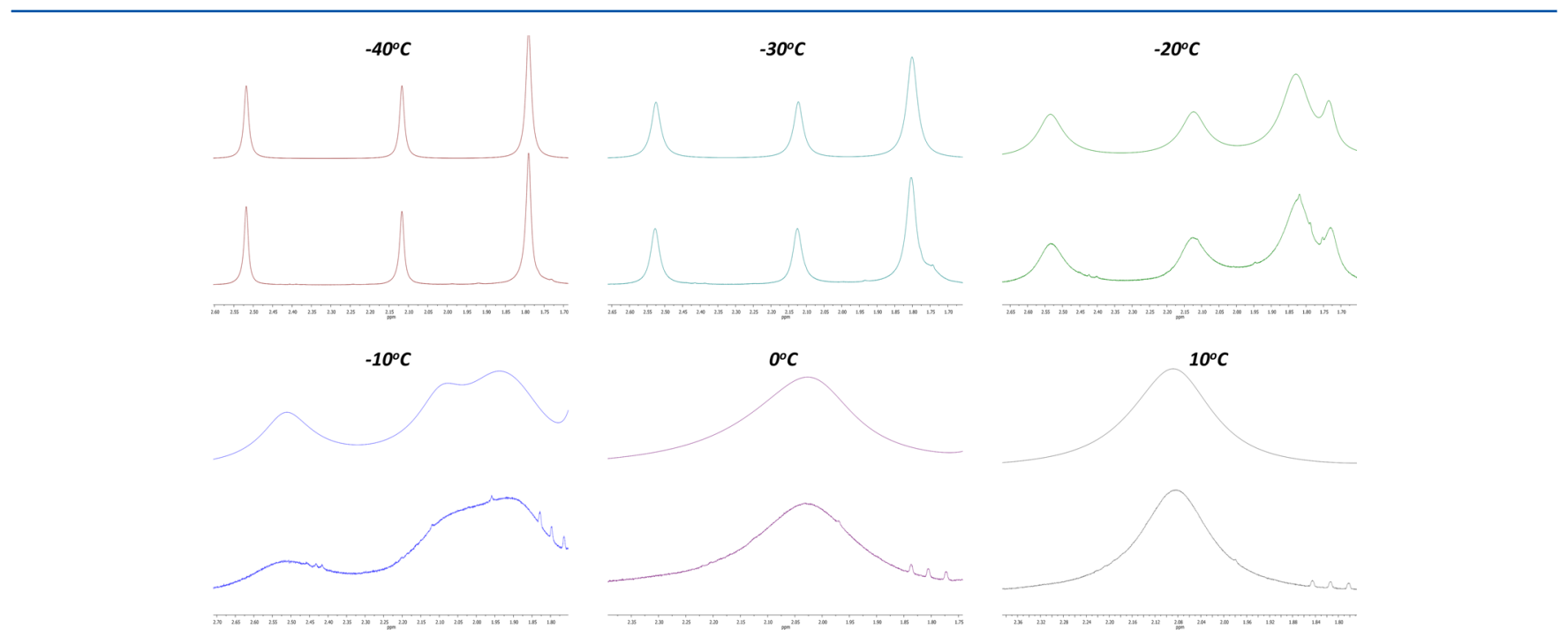

Figure 5. Expansions of the experimental ${ }^{1} \mathrm{H}$ NMR (bottom) and fitting performed by DNMR (top) for ( $\left.\mathrm{Py}\right) \mathrm{PtCl}_{2}(\mathrm{TMA}) \mathbf{1}$ at different temperatures.

1,1,2,2-tetrachloroethane ${ }^{30}$ shows a broad singlet in the aliphatic region, corresponding to the four methyl groups of the coordinated allene (Figure 4a). However, when the temperature decreases, three signals appear, two corresponding to the methyl groups in the noncoordinated double bond of the allene, $\mathrm{Me}^{3}$ and $\mathrm{Me}^{4}$, and a third signal corresponding to the two methyl groups in the coordinated double bond, $\mathrm{Me}^{1}$ and $\mathrm{Me}^{2}$ (Figure 4b).

One spectrum is fitted at a time in the DNMR module. To establish the model, the region to be fitted must be selected and the signals of the protons appearing in the region must be defined (chemical shifts, coupling constants, and intensity). Initially, a region containing no exchanging signals was selected and the protons defined, to first determine the appropriate LB (line broadening parameter) of the spectra (since the wrong value of this parameter will affect the values of the rate constants obtained). Once the LB was calculated for the spectra, a second region containing the exchanging protons was defined. In this case, as well as the chemical shifts, intensity, and LB value, the equilibria occurring between the exchanging protons were defined (rotational and helical movements). The values of the rate constants in these equilibria were the parameters to fit in this case. The simulated spectra obtained for each temperature along with the experimental ones are shown in Figure 5. The rate constants for both processes at different temperatures were obtained by the explained protocol, with the overlap of the fitting of simulated to experimental data being higher than $90 \%$ in all the cases (Table 1; see the SI for full details).

As previously speculated by Vrieze et al., ${ }^{19}$ the $\pi$-face exchange process (rotational movement) showed to be slightly slower than the helical movement for complex $\mathbf{1}$, as also shown when comparing the thermodynamic parameters for both processes in tetrachloroethane, calculated using the Eyring equation (i.e.: $E_{\mathrm{a}}=12 \mathrm{kcal} \mathrm{mol}^{-1}$ for rotational movement in 1; $E_{\mathrm{a}}=9.9 \mathrm{kcal} \mathrm{mol}^{-1}$ for helical movement in $\mathbf{1}$. See the SI for full 
Table 1. Rate Constants $(k)$ Obtained for Rotational and Helical Movements of (Py) $\mathrm{PtCl}_{2}$ (TMA) 1 in 1,1,2,2,Tetrachloroethane

\begin{tabular}{rlcc}
$\begin{array}{c}T \\
\left({ }^{\circ} \mathrm{C}\right)\end{array}$ & $\begin{array}{c}k_{1}\left(\mathrm{~s}^{-1}\right) \text { rotational } \\
\text { movement }\end{array}$ & $\begin{array}{c}k_{2}\left(\mathrm{~s}^{-1}\right) \text { helical } \\
\text { movement }\end{array}$ & $\begin{array}{c}\text { fitting overlap } \\
(\%)\end{array}$ \\
-40 & $1.06 \times 10^{-1}$ & 10.40 & 95 \\
-30 & 5.62 & 24.70 & 94 \\
-20 & 21.63 & 75.76 & 96 \\
-10 & 39.55 & 150.68 & 96 \\
0 & 130.12 & 195.64 & 97 \\
10 & 177.59 & 196.72 & 97 \\
\hline
\end{tabular}

details). The low energy barriers and the small difference in the activation energy of the two processes $\left(\Delta E_{\mathrm{a}} \sim 2 \mathrm{kcal} \mathrm{mol}^{-1}\right)$ point to a mechanism with similar intermediates or transition states in both processes. ${ }^{31}$ Interestingly, the process in tetrachloroethane is slower than that in chloroform $(k=30$ $\mathrm{s}^{-1}$ at $-46{ }^{\circ} \mathrm{C}$ in $\left.\mathrm{CDCl}_{3}\right) .{ }^{19}$

The rotational movement of the platinum around the allene was also studied in complex 2 . The analysis of this complex has not been possible until now using classic techniques, due to decomposition temperatures higher than the coalescence temperature of the signals, which pointed to a very slow rotation. However, with our new SSTD NMR method, we were able to calculate the kinetic parameters of this process in 1,1,2,2-tetrachloroethane- $d_{2}$, by measuring the magnetization transfer in the methyl groups undergoing chemical exchange ( $\pi$-face exchange in this case), as the spin saturation transfer difference parameter $\left(\eta_{\text {SSTD }}\right)$. Plotting this parameter versus the saturation times gave us build-up curves that fitted to the exponential equation allowed us to obtain the values of the rate constants of the process at the different temperatures (see the SI for full details). It is worth noting that the temperatures required for these experiments were higher (above room temperature) than the temperatures used in the line-shape analysis of complex 1 . The calculated kinetic and thermodynamic parameters $\left(\Delta H^{\ddagger}=18.6 \pm 0.4 \mathrm{kcal} \mathrm{mol}^{-1} ; \Delta S^{\ddagger}=-9 \pm\right.$ $1 \mathrm{Cal} \mathrm{mol}^{-1} \mathrm{~K}^{-1} ; E_{\mathrm{a}}(298 \mathrm{~K})=19.2 \pm 0.4 \mathrm{kcal} \mathrm{mol}^{-1} ; \Delta G^{\ddagger}$ $\left.(298 \mathrm{~K})=21.1 \pm 0.4 \mathrm{kcal} \mathrm{mol}^{-1}\right)$ were in accordance with a slow process, as previously suggested, although the movement of the platinum is definitely happening. ${ }^{11}$

Helical and rotational movements have been proposed to be intrinsically related and can occur in an intermolecular (by simple dissociation-recombination mechanism $)^{12}$ or in an intramolecular fashion via $\eta^{1}$-staggered intermediates (or transition states). These staggered intermediates can be either $\eta^{1}$-bent allene structures, if the pathways goes through a Vrieze-Rosenblum mechanism, ${ }^{32}$ or planar $\eta^{1}$-allyl cation structures, in a higher energy process (Scheme 6). ${ }^{26}$ Recently, studies by Widenhoefer et al. in Au-allene complexes showed that the $\pi$-face exchange in those complexes occurs through these staggered $\eta^{1}$-intermediates with the 1,2-metal shift (helical movement) occurring as the first step of the process (although this intermediate was not directly observed in their experiments). ${ }^{23}$

To gather more evidence of the mechanisms in our systems, we repeated the experiments changing the concentration of the platinum complex in the media. A change of the kinetic parameters with the concentration of the complex will be in accordance with an intermolecular mechanism, whereas the opposite will point to an intramolecular mechanism. We found that the rate was not dependent on the concentration at any temperature tested, pointing to an intramolecular process (for full analysis, see the SI).

The thermodynamic parameters were also calculated with different concentrations of the complex. As shown in Figure 6 (see the SI for full analysis), the values for the $E_{\mathrm{a}}$ in both processes for complexes $\mathbf{1}$ and $\mathbf{2}$ suffered scarce variation with the change of concentration of the platinum complex, which suggests that both processes occur intramolecularly through $\eta^{1}$ staggered Pt-allene complexes as possible high energy intermediates. The similar values obtained for the helical and rotational movements in 1 support this proposal $\left(\Delta E_{\mathrm{a}} \sim 2 \mathrm{kcal}\right.$ $\left.\mathrm{mol}^{-1}\right)$. The lower activation energy for the rotational movement of complex 1 vs $2\left(\Delta E_{\mathrm{a}}=7.2 \mathrm{kcal} \mathrm{mol}^{-1}\right)$ is also consistent with the $\eta^{1}$-staggered intermediates, ${ }^{33}$ which could be stabilized by an inductive effect in more substituted allenes, lowering the activation barrier for the 1,2-metal shift (helical movement), that could be the first step in the rotational movement process. This is also supported by the X-ray structures of the TMA and DMA complexes, where a more pronounced slippage toward the central carbon of the allene is observed in complex 1.

Ligand Exchange. It has been proposed before that, at temperatures $>-40{ }^{\circ} \mathrm{C}$, the pyridine ligands in the Py-Pt-allene dissociate, with pyridines substituted with EWG dissociating

Scheme 6. Possible Pathways for the Helical and Rotational Movements of the Platinum around the Allene in a Pt-Allene Complex

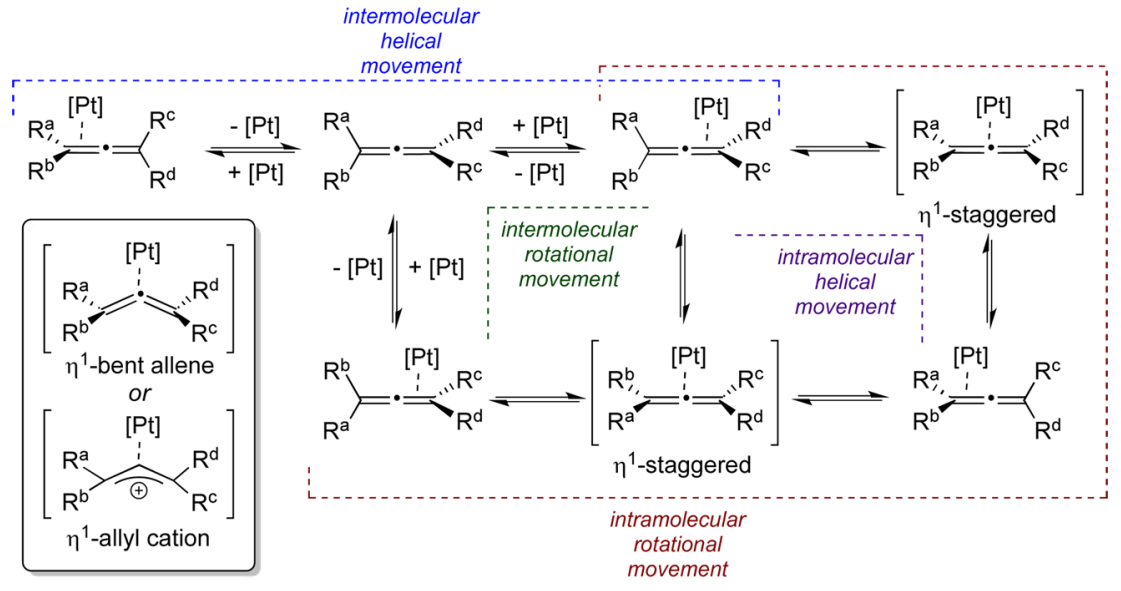




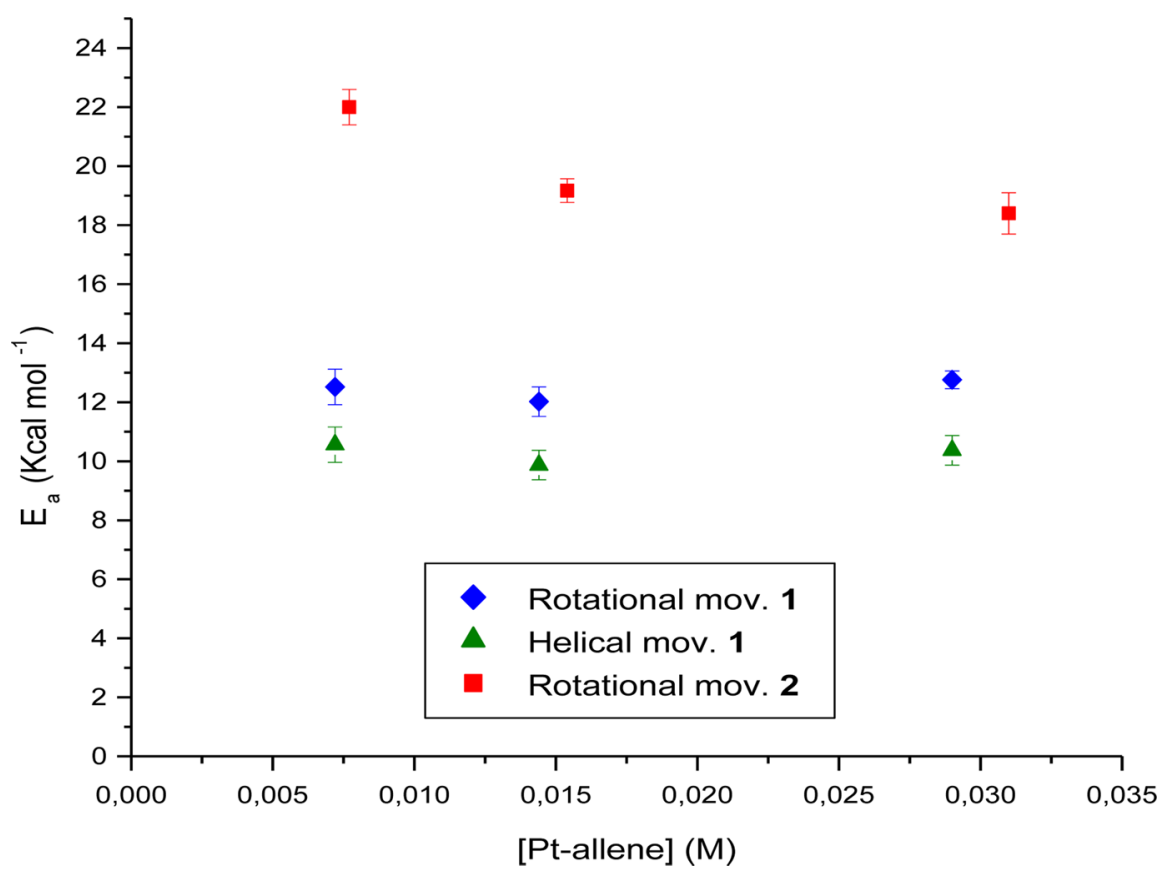

Figure 6. Plot of $E_{\mathrm{a}}$ versus [Pt-allene] for the rotational (blue diamonds) and helical (green triangles) movements of $\mathbf{1}$, and rotational movement (red squares) for 2 .

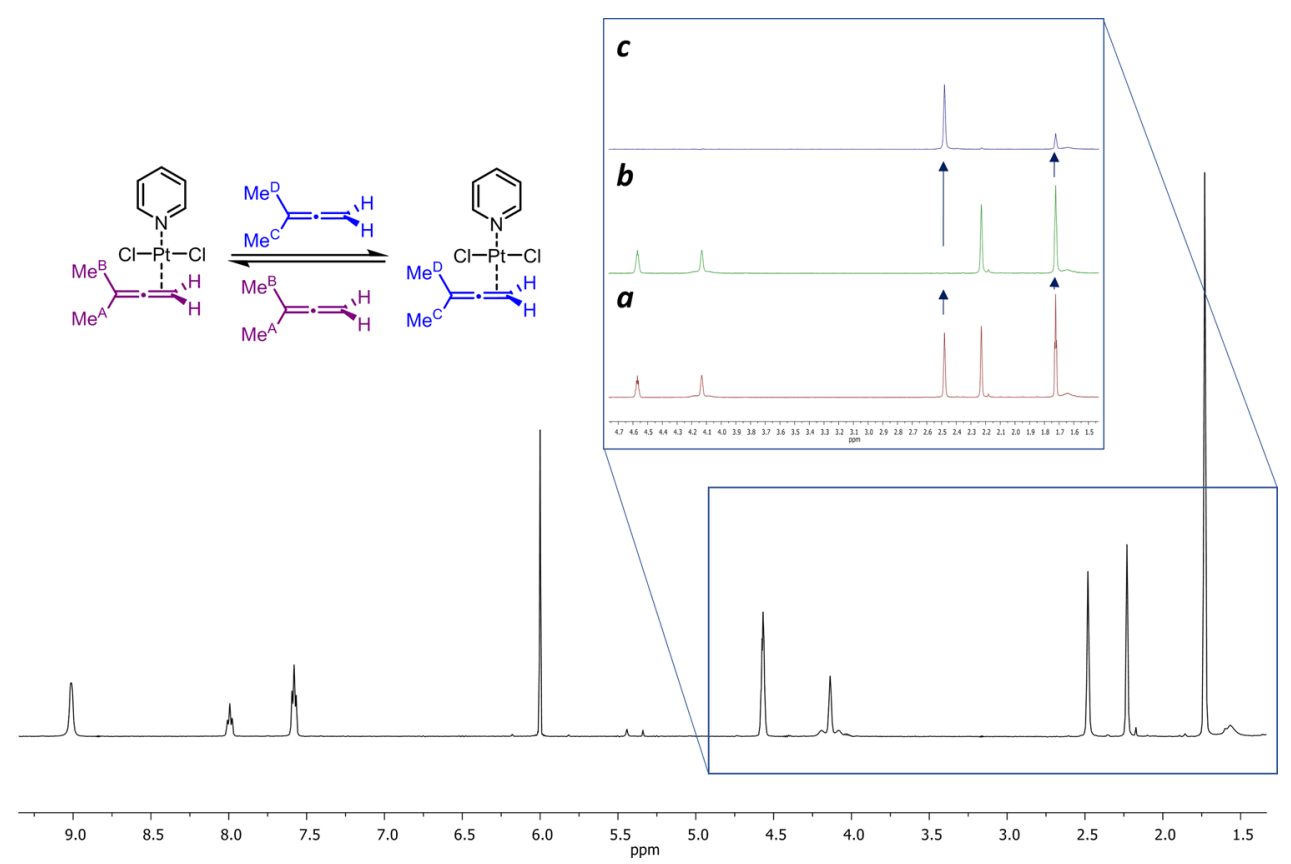

Figure 7. ${ }^{1} \mathrm{H}$ NMR spectra of $(\mathrm{Py}) \mathrm{PtCl}_{2}(\mathrm{DMA}) 2$ at $40{ }^{\circ} \mathrm{C}$ in $1,1,2,2$-tetrachloroethane- $d_{2}$. (a) ${ }^{1} \mathrm{H}$ NMR expansion of the region from 1.4 to 5.0 ppm before irradiation. (b) Same region after the irradiation of the methyl group at $2.48 \mathrm{ppm}$. (c) Difference spectrum [(a) - (b)].

easier. Besides, in the work reported by Vrieze et al., it was reported that dissociation of the tetramethylallene did not occur at temperatures below $80{ }^{\circ} \mathrm{C}$, or in the presence of free TMA. ${ }^{19 \mathrm{~b}}$ However, no proper kinetic study of the ligand exchange was carried out.

This process of ligand exchange in Pt-allene complexes is important since it is the starting point of most of the catalytic cycles. Therefore, we decided to study it in more depth with Ptallene complexes bearing different $\mathrm{N}$-containing ligands in the four- and five-coordinative structures using our SSTD NMR technique. It is worth noting here that this is the first time that the SSTD NMR method has been applied in the study of an intermolecular chemical exchange. The good results obtained for our complexes emphasize the relevance of this method and the potential for further application to the study of other ligand exchange processes in organometallic systems.

We first applied the SSTD NMR method to study the ligand exchange process in a mixture of $(\mathrm{Py}) \mathrm{PtCl}_{2}(\mathrm{DMA}) 2$ in the presence of free 1,1-dimethylallene (DMA). A preliminary experiment irradiating one of methyl groups of the coordinated allene showed that there was a transfer of saturation between this signal and the signal corresponding to the methyl groups in 
the free allene, which indeed shows that ligand exchange is occurring. This process of ligand exchange appeared to be quicker than the internal rotation, and a temperature range of 293-313 K was enough to observe solely the ligand exchange, with no signs of the intramolecular rotational movement happening (Figure 7 ). ${ }^{34}$

With the right conditions in hand, we calculated the rate constants at different temperatures for the ligand exchange process applying the SSTD NMR technique. We obtained build-up curves, which fitting gave us the rate constants at different temperatures (Figure 8). This allowed us to calculate

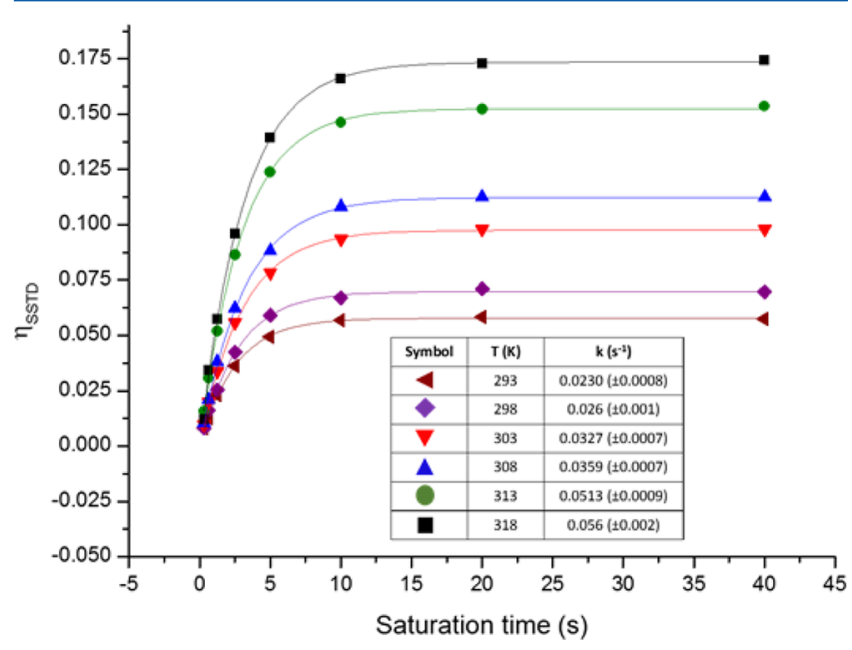

Figure 8. Plots of the transfer of magnetization $\left(\eta_{\mathrm{SSTD}}\right)$ versus saturation time (s) at different temperatures for the mixture (Py) $\mathrm{PtCl}_{2}(\mathrm{DMA}) 2$ (1 equiv) + DMA (1 equiv), and table with the obtained rate constants after fit of the exponential curves.

the thermodynamic parameters of the ligand exchange using the Eyring equation: $\Delta H^{\ddagger}=6.4 \pm 0.3 \mathrm{kcal} \mathrm{mol}^{-1} ; \Delta S^{\ddagger}=-44.4$ $\pm 1.0 \mathrm{Cal} \mathrm{mol}^{-1} \mathrm{~K}^{-1} ; E_{\mathrm{a}}(298 \mathrm{~K})=6.9 \pm 0.3 \mathrm{kcal} \mathrm{mol}^{-1} ; \Delta G^{\ddagger}$ $(298 \mathrm{~K})=19.6 \pm 0.3 \mathrm{kcal} \mathrm{mol}^{-1}$ (see the SI for details). The value of the energy of activation for the ligand exchange confirms that this process is much faster than the rotational movement in the complex studied $\left(\Delta E_{\mathrm{a}}=12.2 \mathrm{kcal} \mathrm{mol}^{-1}\right)$.

Competitive ligand-dependent and ligand-independent pathways are common for coordinatively unsaturated transitionmetal complexes and have been proposed before in other metal-allene complexes. ${ }^{35}$ The allene-dependent mechanism is consistent with an associative mechanism involving direct attack of the free allene at the metal to form a bis(allene) intermediate, followed by rapid allene dissociation, or rapid solvation, followed by rapid associative exchange with free allene (Scheme 7). On the contrary, in the dissociative mechanism, the first step would be the dissociation of the allene ligand, and this is normally the rls in the process. Both pathways can be differentiated measuring the kinetic behavior with different concentrations of free allene in the media. The change in the speed of the process by changing the concentration of ligand, and a two-term rate law, would point to an associative mechanism, whereas, if no change in speed is observed with different concentrations of the external allene, it would indicate that the process occurs through a dissociative mechanism.

When the kinetic and thermodynamic parameters were calculated using different concentrations of free 1,1-dimethylallene (DMA) in the same system as above, minimum variations were observed in the rate constants and in the thermodynamic parameters (see the SI for full details), suggesting that the dissociative mechanism is occurring with this complex at the temperatures studied. ${ }^{36}$

Dissociative mechanisms for ligand exchange have been observed for $\mathrm{d}^{8}$ complexes when the geometry is distorted from square planar or if the coordination number is higher than four. ${ }^{37}$ For comparison with the four-coordinated Pt-allene complex, and to confirm the dissociative mechanism, we also studied the ligand exchange process in the five-coordinated complex (DAD) $\mathrm{PtCl}_{2}$ (DMA) 3. As mentioned before, the stability of this complex in chlorinated solvents was poor and the allene ligand exchange process was found to be slow $\left(\eta_{\text {SSTD }}\right.$ $=0.0124$ at $298 \mathrm{~K}$ for a saturation time of $40 \mathrm{~s}$ ). We found that changing the solvent to THF improved both, stability and speed of the exchange $\left(\eta_{\mathrm{SSTD}}=0.4362\right.$ at $298 \mathrm{~K}$ for a saturation time of $40 \mathrm{~s}$ ). This complex could not be isolated due to decomposition issues, so for the SSTD NMR study, samples were prepared in situ from a solution in THF- $d^{8}$ of the ethylene complex and an excess of dimethylallene displacing the ethylene from the media by bubbling nitrogen in the solution during $20 \mathrm{~min}$. Although this methodology made it more challenging to precise the concentration of the complex in the sample, we could still obtain the build-up curves, the rate constants at different temperatures, and the thermodynamic

Scheme 7. Possible Pathways for the Ligand Exchange in Pt-Allene Complexes

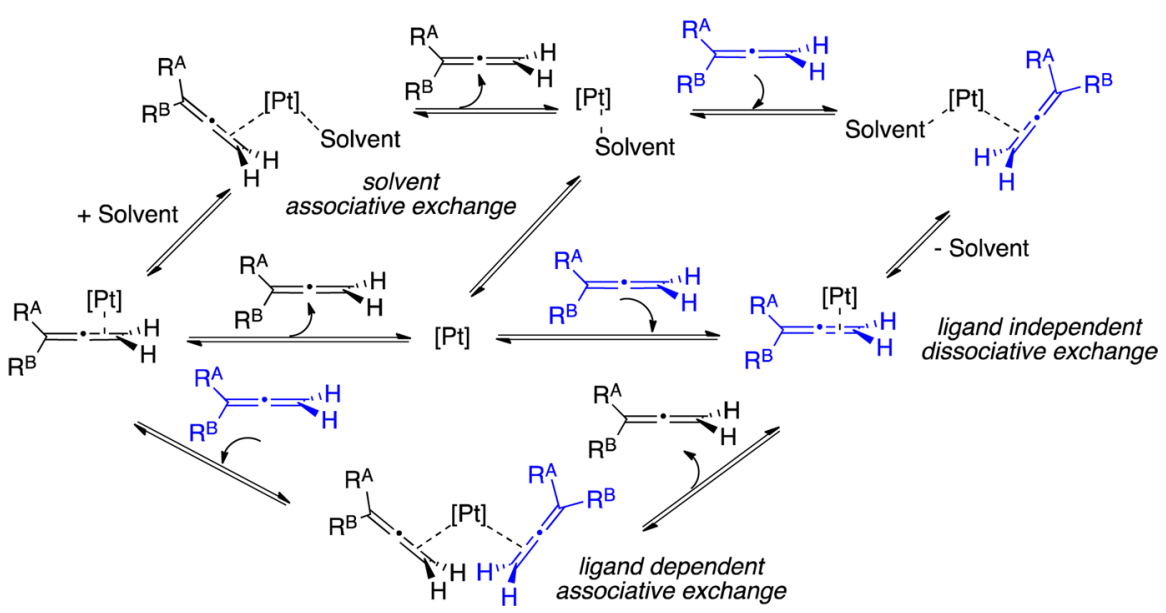




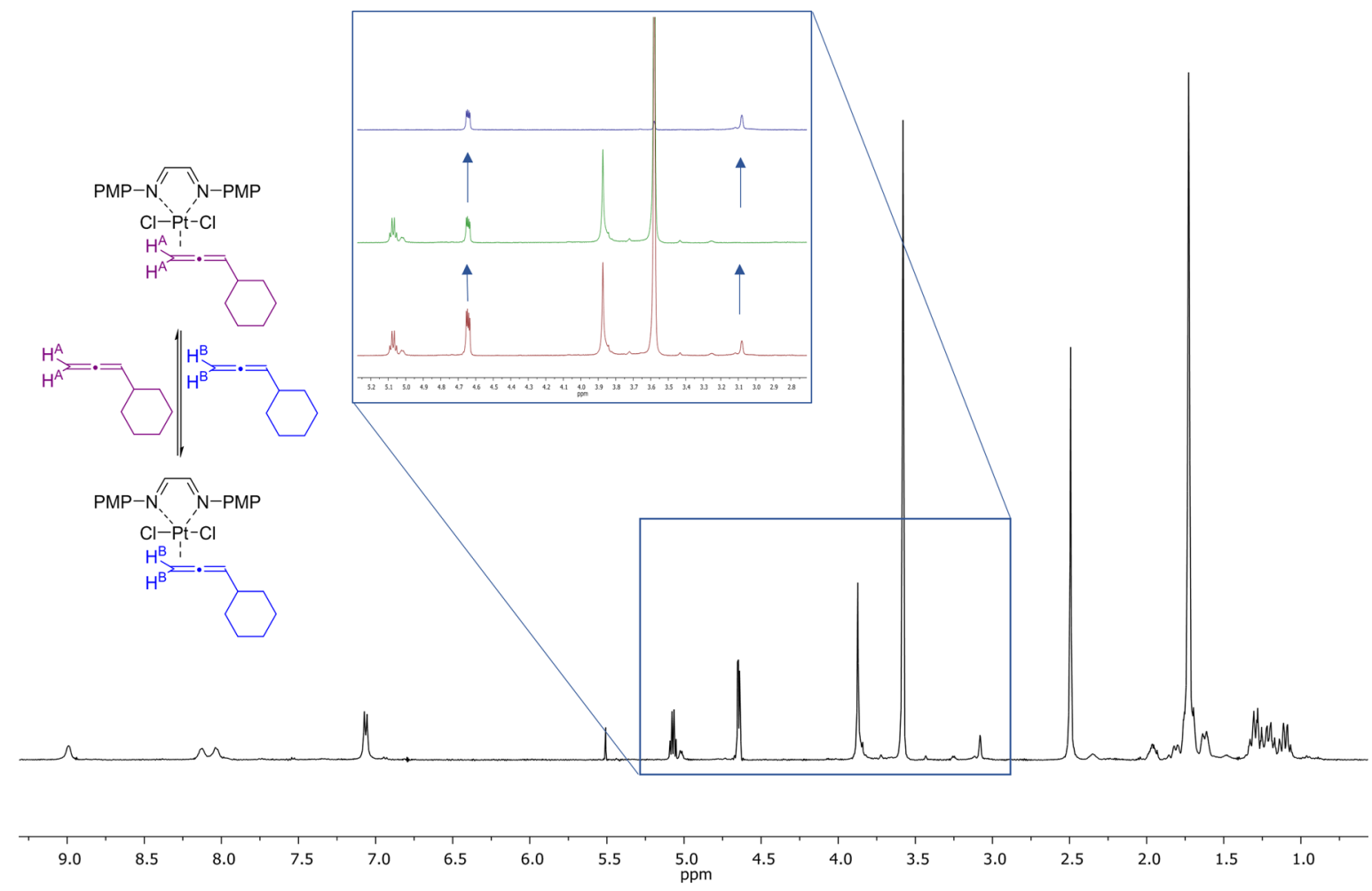

Figure 9. ${ }^{1} \mathrm{H}$ NMR spectra of (DAD) $\mathrm{PtCl}_{2}(\mathrm{CHA}) 4$ (1 equiv) + $\mathrm{CHA}$ (2 equiv) at $25{ }^{\circ} \mathrm{C}$ in THF- $d_{8}$. (a) ${ }^{1} \mathrm{H}$ NMR expansion of the region from 2.7 to $5.2 \mathrm{ppm}$ before irradiation. (b) Same region after the irradiation of the protons at $3.08 \mathrm{ppm}$. (c) Difference spectrum [(a) - (b)].

parameters $\left(\Delta H^{\ddagger}=4.5 \pm 0.6 \mathrm{kcal} \mathrm{mol}^{-1} ; \Delta S^{\ddagger}=-48 \pm 2 \mathrm{Cal}\right.$ $\mathrm{mol}^{-1} \mathrm{~K}^{-1} ; E_{\mathrm{a}}(298 \mathrm{~K})=5.1 \pm 0.6 \mathrm{kcal} \mathrm{mol}^{-1} ; \Delta G^{\ddagger}(298 \mathrm{~K})=$ $\left.18.7 \pm 0.6 \mathrm{kcal} \mathrm{mol}^{-1}\right)$ for the ligand exchange process of complex 3 and free DMA. Although measured in different solvents, these values are in the same range of the ones obtained for the four-coordinated complex 2, suggesting a dissociative mechanism in both cases. The fact that the process is faster in THF when compared to TCE might point to a more complex mechanism with fast solvation of the free platinum after allene dissociation.

In order to confirm the dissociative mechanism with a more stable, isolable five-coordinated complex, we studied the ligand exchange process using the SSTD NMR method with complex 4 and free cyclohexylallene (CHA). Similarly to complex 3 , the stability of $\mathbf{4}$ was better and the speed of ligand exchange faster in THF as solvent when compared to TCE or chloroform. This is not surprising as the donicity of THF is much higher than the chlorinated solvents, normally considered nearly $0 .^{25}$ This is in agreement with the observations of allene dissociation mentioned when describing the synthesis of the complexes and suggests further stabilization by solvation and possible coordination of the THF at some stage in the mechanism. To investigate the ligand exchange process in this complex, a mixture of the platinum-allene complex and free allene was prepared in THD- $d^{8}$. The signal chosen for irradiation was the signal of the external protons of the coordinated allene, which appears at $3.08 \mathrm{ppm}$ in the ${ }^{1} \mathrm{H}$ NMR (Figure 9). Figure 10 depicts the build-up curves at different temperatures along with the obtained rate constants. With the values of the rate constants, the thermodynamic parameters were calculated using the Eyring equation as shown in Figure 11.

The value for the activation energy for the diazadiene complex with cyclohexylallene is higher than the one obtained

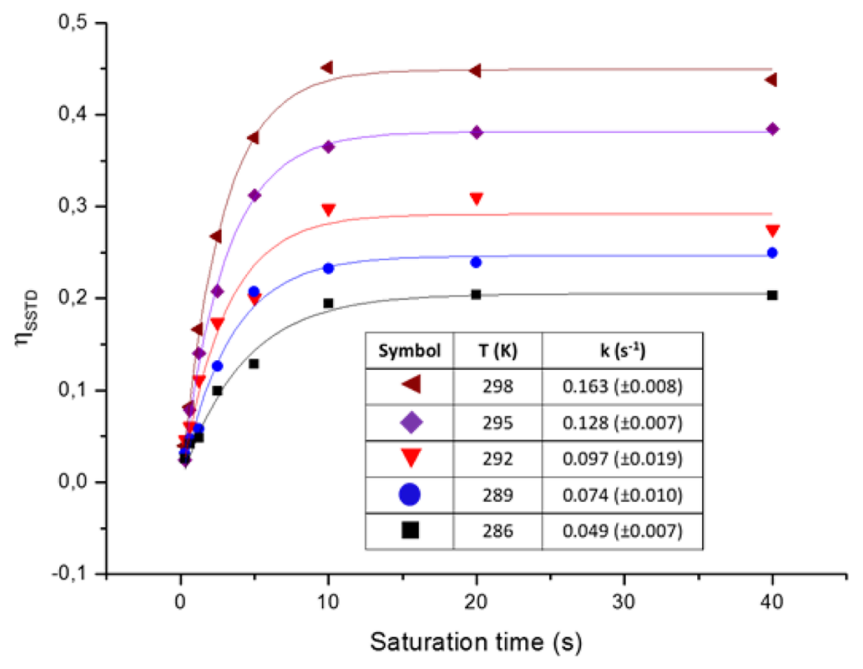

Figure 10. Plots of the transfer of magnetization $\left(\eta_{\text {SSTD }}\right)$ versus saturation time at different temperatures for the mixture (DAD)$\mathrm{PtCl}_{2}(\mathrm{CHA}) 4$ (1 equiv) + CHA (2 equiv), and table with the obtained rate constants after fit of the exponential curves.

for the analogous complex with dimethylallene $\left(\Delta E_{\mathrm{a}}=11.6 \mathrm{kcal}\right.$ $\mathrm{mol}^{-1}$ ), which points to a slower ligand exchange process for the cyclohexylallene. This will further support a dissociative mechanism, as 1,1-DMA is sterically more hindered than $\mathrm{CHA}$ and, therefore, easier to dissociate from the platinum coordination sphere.

Once again, to check the dependence of the ligand exchange process with the concentration of free allene, SSTD NMR experiments were carried out changing the concentration of CHA. The calculated rate constants with different amounts of free allene are shown in Figure 12 (for full analysis, see the SI). 


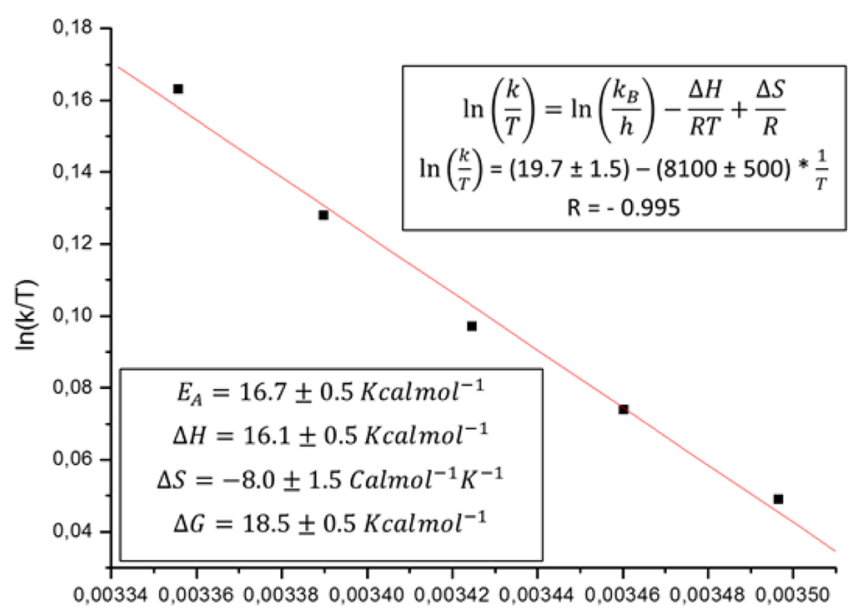

$1 / \mathrm{T}$

Figure 11. Eyring plot for the mixture (DAD) $\mathrm{PtCl}_{2}(\mathrm{CHA}) 4$ (1 equiv) $+\mathrm{CHA}$ (2 equiv). Slope and intercept values were used to calculate the enthalpy and entropy of activation, respectively.

Again, no two-term rate low was observed in this system, and although the variation in the values is slightly bigger than in previous cases, possibly due to the involvement of the solvent in the ligand exchange as mentioned earlier, we can still observe no significant change in the kinetic or thermodynamic parameters with concentration of free allene, and therefore, a dissociative mechanism is proposed for this complex too.

Although comparison of the three studied processes has to be done with caution due to the different solvent and slightly different temperature range used in the analysis of the Py and $\mathrm{DAD}$ complexes, we observed a linear compensation effect when plotting values of $\Delta H^{\ddagger}$ versus $\Delta S^{\ddagger}$ for the three processes, which would further support the same type of mechanism along the series (see the SI for details). ${ }^{38}$
In summary, we have applied different NMR techniques to the study of the fluxional behavior of Pt-allene complexes with $\mathrm{N}$-containing ligands in four and five coordination mode. We have obtained the kinetic and thermodynamic parameters for the three main processes occurring in solution: the ligand exchange, the helical and the rotational movements. Our results show that the helical and rotational movements occur intramolecularly and are closely related to each other, confirming $\eta^{1}$-staggered structures as possible intermediates and suggesting that the helical movement could be the first step in the rotational pathway in the complexes studied. We have also revealed that the ligand exchange occurs mainly via a ligand-independent dissociative mechanism, where coordinating solvents might be involved in the stabilization of the intermediates.

Our results are in agreement with previous speculations on the behavior of platinum complexes, providing the lacking experimental evidence for comparison with other metals. For example, the results presented here, compared with those reported for Au-allene complexes, ${ }^{23}$ show a divergent coordination in the ground state and behavior of Pt-allene complexes regarding ligand exchange, but related pathways for the rotational movement, although with different activation energies, which might explain the divergent reactivity observed with these two metals.

Although platinum complexes used in catalysis are most commonly free of ligands, the complexes studied in this work have shown to be active catalysts in the dihydroalkoxylation reaction of allenes. ${ }^{10}$ Therefore, the information obtained with the complexes studied in this work can be extrapolated to real catalytic cycles where the coordination of the platinum to the allenes is generally the first step in the cycle. Understanding this coordination is a crucial step forward to the understanding of mechanisms involving Pt-allene systems, which is key to control the processes toward the development of new reactions and more complex structures.

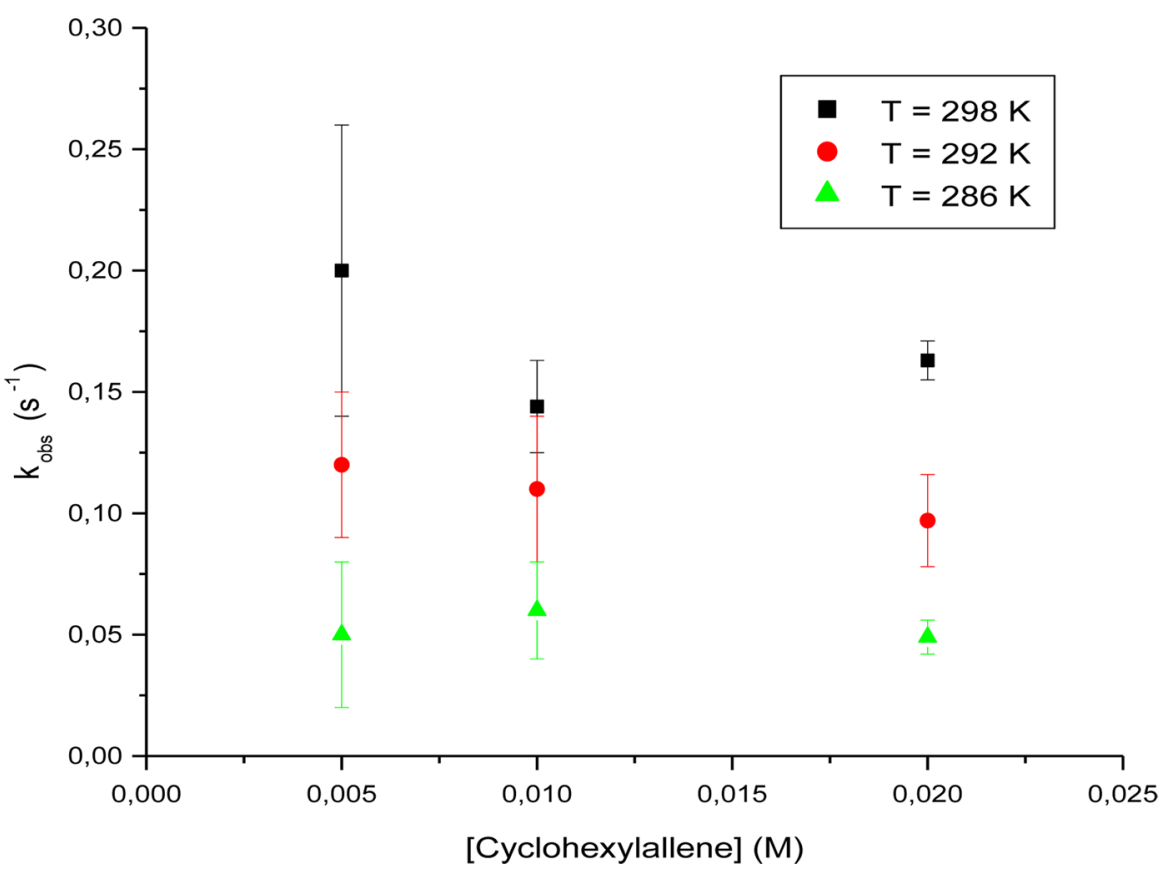

Figure 12. Plot of $k_{\mathrm{obs}}$ versus [CHA] for the ligand exchange of 4 at different temperatures: $298 \mathrm{~K}$ (black squares), $292 \mathrm{~K}$ (red dots), and $286 \mathrm{~K}$ (green triangles). 
Besides, mechanisms of ligand exchange are very important not only for these complexes and the specific allene but for the whole field of organometallic chemistry and metal catalysis, and we are convinced that the application of our new SSTD NMR method will contribute to the discovery of new twists and turns in other organometallic systems.

\section{EXPERIMENTAL SECTION}

(Py) $\mathrm{PtCl}_{2}$ (ethylene). This compound was prepared from the Zeise's salt according to reported procedures. ${ }^{14}$ Pyridine $(1 \mathrm{mmol})$ was added dropwise to a stirred solution of the Zeise's salt $(1.1 \mathrm{mmol})$ in distilled water $(12 \mathrm{~mL} / \mathrm{mmol})$. The product precipitated. After stirring for an additional $40 \mathrm{~min}$, the solid was isolated by filtration and washed with water. From $50 \mathrm{mg}(0.136 \mathrm{mmol})$ of the Zeise's salt, the platinum alkene complex $(37.8 \mathrm{mg}, 74 \%)$ was obtained as a yellow solid. ${ }^{1} \mathrm{H}$ $\operatorname{NMR}\left(500 \mathrm{MHz}, \mathrm{CDCl}_{3}, 25{ }^{\circ} \mathrm{C}\right) \delta(\mathrm{ppm})=8.94(\mathrm{~d}, J=3.6 \mathrm{~Hz}, 2 \mathrm{H}$, Py), $7.95(\mathrm{dt}, J=7.7,1.5 \mathrm{~Hz}, 1 \mathrm{H}, \mathrm{Py}), 7.53(\mathrm{~m}, 2 \mathrm{H}, \mathrm{Py}), 4.91\left(\mathrm{~s}, J_{P t-H}=\right.$ $\left.60 \mathrm{~Hz}, 3 \mathrm{H},=\mathrm{CH}_{2}\right) . \mathrm{MP}=107.4-108.9^{\circ} \mathrm{C}$.

(Py) $\mathrm{PtCl}_{2}$ (TMA) 1. This compound had been previously reported. ${ }^{17}$ To a suspension of $(\mathrm{Py}) \mathrm{PtCl}_{2}$ (ethylene) $(1 \mathrm{mmol})$ in methanol $(0.37$ $\mathrm{mL} / \mathrm{mmol})$ was added the tetramethylallene $(2 \mathrm{mmol})$. After $10 \mathrm{~min}$, the platinum-allene complex precipitated and was isolated by centrifugation. From $15 \mathrm{mg}(0.0402 \mathrm{mmol})$ of the platinum-alkene complex, the platinum-allene complex $(14.7 \mathrm{mg}, 83 \%)$ was obtained as a yellow solid. ${ }^{1} \mathrm{H} \mathrm{NMR}\left(500 \mathrm{MHz}, \mathrm{CDCl}_{2} \mathrm{CDCl}_{2}, 25{ }^{\circ} \mathrm{C}\right) \delta(\mathrm{ppm})=$ $8.86(\mathrm{~d}, J=5.2 \mathrm{~Hz}, 2 \mathrm{H}, \mathrm{Py}), 7.91(\mathrm{t}, J=7.7 \mathrm{~Hz}, 1 \mathrm{H}, \mathrm{Py}), 7.58(\mathrm{~m}, 2 \mathrm{H}$, py), 2.11 (br s, $\left.12 \mathrm{H}, 4 \mathrm{CH}_{3}\right) . \mathrm{MP}=116.6-117.9^{\circ} \mathrm{C}$.

(Py) $\mathrm{PtCl}_{2}$ (DMA) 2. This compound had been previously reported. ${ }^{17} \mathrm{To}$ a solution of $(\mathrm{Py}) \mathrm{PtCl}_{2}$ (ethylene) $(1 \mathrm{mmol})$ in DCM $(70 \mathrm{~mL} / \mathrm{mmol})$ was added the allene $(1 \mathrm{mmol})$. The solution was stirred for $10 \mathrm{~min}$, and then the mixture was filtered through Celite and the solvent was evaporated, affording the platinum-allene complex. From $25 \mathrm{mg}(0.067 \mathrm{mmol})$ of the platinum-alkene complex, the platinum-allene complex ( $31.2 \mathrm{mg}$, quantitative) was obtained as a yellow solid. ${ }^{1} \mathrm{H}$ NMR $\left(500 \mathrm{MHz}, \mathrm{CDCl}_{2} \mathrm{CDCl}_{2}, 25{ }^{\circ} \mathrm{C}\right) \delta(\mathrm{ppm})=$ $8.94(\mathrm{~d}, J=5.2 \mathrm{~Hz}, 2 \mathrm{H}, \mathrm{Py}), 7.99(\mathrm{t}, J=7.7 \mathrm{~Hz}, 1 \mathrm{H}, \mathrm{Py}), 7.58(\mathrm{t}, J=$ $6.9 \mathrm{~Hz}, 2 \mathrm{H}, \mathrm{Py}), 4.17-4.04\left(\mathrm{~m}, J_{P t-H}=60 \mathrm{~Hz}, 2 \mathrm{H},=\cdot=\mathrm{CH}_{2}\right), 2.46(\mathrm{~s}$, $\left.3 \mathrm{H}, \mathrm{CH}_{3}{ }^{\mathrm{A}}\right), 2.21\left(\mathrm{~s}, 3 \mathrm{H}, \mathrm{CH}_{3}{ }^{\mathrm{B}}\right) ;{ }^{195} \mathrm{Pt} \mathrm{NMR}\left(107.2 \mathrm{MHz} \mathrm{CDCl}_{3}, 25\right.$ $\left.{ }^{\circ} \mathrm{C}\right) \delta(\mathrm{ppm})=2254.24 . \mathrm{MP}=114.6-115.9{ }^{\circ} \mathrm{C}$.

(DAD) $\mathrm{PtCl}_{2}$ (ethylene). This compound was prepared from the Zeise's salt according to reported procedures. ${ }^{22} \mathrm{~A}$ solution of the Zeise's salt $(1 \mathrm{mmol})$ in methanol $(10 \mathrm{~mL} / \mathrm{mmol})$ was added dropwise to a solution of the $\alpha$-diimine $(1 \mathrm{mmol})$ in dichloromethane $(100 \mathrm{~mL}$ / $\mathrm{mmol}$ ). The solution was stirred for $10 \mathrm{~min}$. After filtration over Celite, the solvent was evaporated to dryness without heating the sample. From $100 \mathrm{mg}(0.271 \mathrm{mmol})$ of the Zeise's salt, the platinum alkene complex (139.1 mg, 91\%) was obtained as a red solid. ${ }^{1} \mathrm{H}$ NMR $\left(500 \mathrm{MHz}, \mathrm{CDCl}_{3}, 25^{\circ} \mathrm{C}\right) \delta(\mathrm{ppm})=8.91(\mathrm{~s}, 2 \mathrm{H}, \mathrm{CH}=\mathrm{N}), 7.98(\mathrm{~d}, J$ $=9.0 \mathrm{~Hz}, 4 \mathrm{H}, \mathrm{PMP}), 7.03(\mathrm{~d}, J=9.0 \mathrm{~Hz}, 4 \mathrm{H}, \mathrm{PMP}), 3.90(\mathrm{~s}, 6 \mathrm{H}$, $\left.\mathrm{OCH}_{3}\right), 3.89\left(\mathrm{~s}, 4 \mathrm{H}, \mathrm{CH}_{2}=\mathrm{CH}_{2}\right) . \mathrm{IR}=1599(\mathrm{C}=\mathrm{N}), 1588(\mathrm{C}=\mathrm{C})$, $1264(\mathrm{C}-\mathrm{O}) . \mathrm{MP}=282.1-284.0^{\circ} \mathrm{C} .^{37}$

(DAD) $\mathrm{PtCl}_{2}$ (DMA) 3. This compound was prepared in situ from a mixture of the (DAD) $\mathrm{PtCl}_{2}$ (ethylene) $(1 \mathrm{mmol})$ and the dimethylallene $(1 \mathrm{mmol})$ in THF- $d^{8}(100 \mathrm{~mL} / \mathrm{mmol})$. A nitrogen flow was fluxed though the solution for $10 \mathrm{~min}$ to make sure that all the ethylene was removed. ${ }^{1} \mathrm{H}$ NMR $\left(500 \mathrm{MHz}\right.$, THF, $\left.25^{\circ} \mathrm{C}\right) \delta(\mathrm{ppm})=$ $8.92(\mathrm{~m}, 2 \mathrm{H}, \mathrm{CH}=\mathrm{N}), 7.91(\mathrm{~m}, 4 \mathrm{H}, \mathrm{Ar} \mathrm{PMP}), 7.02(\mathrm{br} \mathrm{s}, 4 \mathrm{H}, \mathrm{Ar}$ PMP), $3.85\left(\mathrm{~s}, 6 \mathrm{H}, 2 \mathrm{OCH}_{3}\right), 3.08\left(\mathrm{~m}, 2 \mathrm{H},==\mathrm{CH}_{2}\right), 2.06(\mathrm{~s}, 3 \mathrm{H}$, $\left.\mathrm{CH}_{3}{ }^{\mathrm{A}}\right) ; 1.77\left(\mathrm{~s}, 3 \mathrm{H}, \mathrm{CH}_{3}{ }^{\mathrm{B}}\right) .{ }^{13} \mathrm{C} \mathrm{NMR}\left(\mathrm{MHz}, \mathrm{THF}, 25^{\circ} \mathrm{C}\right) \delta(\mathrm{ppm})=$ 165.9 $(\mathrm{C}=\mathrm{N}), 161.6\left(\mathrm{OC}^{\mathrm{q}}\right), 126.6\left(\mathrm{C}^{\mathrm{q}}\right), 123,5\left(\mathrm{C}^{\mathrm{Ar}} \mathrm{PMP}\right), 115.5$ (C ${ }^{A r}$ PMP), 115,1 ( $\mathrm{C}^{\mathrm{q}}$ Allene $), 94.6$ ( $\mathrm{C}^{\mathrm{q}}$ Allene $), 56.0\left(\mathrm{OCH}_{3}\right), 24.4$ $\left(\mathrm{CH}_{3}{ }^{\mathrm{A}}\right), 21.1\left(\mathrm{CH}_{3}^{\mathrm{B}}\right), 19.1\left(=\mathrm{CH}_{2}\right)^{37}$

(DAD) $\mathrm{PtCl}_{2}$ (CHA) 4. To a solution of the platinum-alkene complex $(1 \mathrm{mmol})$ in DCM $(70 \mathrm{~mL} / \mathrm{mmol})$ was added the allene $(1 \mathrm{mmol})$. The solution was stirred for $10 \mathrm{~min}$, and then the mixture was filtered through Celite and the solvent was evaporated, affording the platinumallene complex. From $35 \mathrm{mg}(0.062 \mathrm{mmol})$ of the platinum-alkene complex, the platinum-allene complex $(37.2 \mathrm{mg}, 91 \%)$ was obtained as a red solid. ${ }^{1} \mathrm{H}$ NMR $\left(500 \mathrm{MHz}\right.$, THF, $\left.25{ }^{\circ} \mathrm{C}\right) \delta(\mathrm{ppm})=8.96(\mathrm{br} \mathrm{s}$,
$2 \mathrm{H}, \mathrm{CH}=\mathrm{N}$ ), $8.06(\mathrm{~m}, 4 \mathrm{H}, \mathrm{Ar} \mathrm{PMP}), 7.04(\mathrm{~d}, J=8.8 \mathrm{~Hz}, 4 \mathrm{H}, \mathrm{Ar}$ PMP), $5.03(\mathrm{dt}, J=6.1,3.0 \mathrm{~Hz}, 1 \mathrm{H},==\mathrm{CH}), 3.86\left(\mathrm{~s}, 6 \mathrm{H}, 2 \mathrm{OCH}_{3}\right)$, 3.09 (dd, $\left.J=3.0,1.8 \mathrm{~Hz}, 2 \mathrm{H},=\cdot=\mathrm{CH}_{2}\right), 2.35(\mathrm{~m}, 1 \mathrm{H}, \mathrm{CH} \mathrm{Cy})$, $1.73-1.82\left(\mathrm{~m}, 4 \mathrm{H}, 2 \mathrm{CH}_{2} \mathrm{Cy}\right), 1.18-1.84\left(\mathrm{~m}, 6 \mathrm{H}, 3 \mathrm{CH}_{2} \mathrm{Cy}\right) .{ }^{13} \mathrm{C}$ $\operatorname{NMR}\left(\mathrm{MHz}, \mathrm{THF}, 25^{\circ} \mathrm{C}\right) \delta(\mathrm{ppm})=162.6(\mathrm{C}=\mathrm{N}), 158.1\left(\mathrm{OC}^{\mathrm{q}}\right)$, $136.4\left(\mathrm{C}^{\mathrm{q}}\right), 126,4$ ( $\left.\mathrm{C}^{\mathrm{Ar}} \mathrm{PMP}\right), 115.6\left(\mathrm{C}^{\mathrm{Ar}} \mathrm{PMP}\right), 115.4(==\mathrm{CH})$, 96.5 ( $\mathrm{C}^{\mathrm{q}}$ Allene), $56.1\left(\mathrm{OCH}_{3}\right), 41,1(\mathrm{CH} \mathrm{Cy}), 34.4\left(2 \mathrm{CH}_{2} \mathrm{Cy}\right), 27.4$ $\left(\mathrm{CH}_{2} \mathrm{Cy}\right), 27.1\left(2 \mathrm{CH}_{2} \mathrm{Cy}\right), 16.1\left(=\mathrm{CH}_{2}\right) . \mathrm{IR}=1593(\mathrm{C}=\mathrm{N}), 1511$ $(\mathrm{C}=\mathrm{C}), 1256(\mathrm{C}-\mathrm{O}) . \mathrm{MP}=350-352{ }^{\circ} \mathrm{C}($ decomposition$) .{ }^{39}$

The analysis of the temperature-dependent ${ }^{1} \mathrm{H}$ NMR of the (Py) $\mathrm{PtCl}_{2}$ (TMA) 1 was performed using the DNMR module of the TopSpin. This program simulates the spectra by setting up and refining the model parameters in order to adjust them to the experimentally obtained NMR. In the DNMR line-shape analysis tool, the parameters have to be defined in the parameter panel, starting with the chemical shift range of the spectra to be fitted. Secondly, the spin systems and each of the nuclei included in them must be set (LB, intensity or chemical shifts). The reactions (chemical exchanges) occurring in those systems also have to be defined. Finally, the parameters to be refined can be chosen, and the software then gives the best possible overlap with the measured spectra. ${ }^{40}$

General considerations for the SSTD NMR experiments: A standard 1D STD NMR pulse sequence provided by the manufacturer ("stddiff", Bruker) was used for the experiments. They were carried out on a $11.7 \mathrm{~T}$ high-resolution Bruker NMR spectrometer (500 $\mathrm{MHz})$ equipped with an inverse triple resonance $(\mathrm{H} / \mathrm{C} / \mathrm{N}) \mathrm{z}$-gradient probe head. The total saturation time for a given experiment was built by a chain of " $n$ " Gaussian pulses of $50 \mathrm{~ms}$ length, with a maximum field strength $\gamma B_{1}$ of $104 \mathrm{~Hz}$, providing a saturation time of " $0.05 \cdot n$ " seconds. To avoid relaxation artifacts, all the experiments within a build-up curve had total duration constant; i.e., the addition of the relaxation delay plus the saturation time and the acquisition time was kept constant (42 s) along the whole set of experiments. On-resonance frequency was selected at the chemical shift of one of the ${ }^{1} \mathrm{H}$ signals of the exchanging sites, and the off-resonance (reference NMR spectrum) frequency was set in all the cases to $40 \mathrm{ppm}$. For all the SSTD NMR experiments, the spectral width was selected to cover the two signals of interest and centered (O1) at the frequency of the irradiated signal. Integration of signals was carried out using TopSpin 3.1. ${ }^{9}$

Crystallographic data for complexes $\mathbf{1}$ and $\mathbf{2}$ have been deposited at the Cambridge Crystallographic Data Centre (CCDC 1507881 (1) and CCDC $1507882(2))$ and can be obtained free of charge on their Web site (http://www.ccdc.cam.ac.uk).

\section{ASSOCIATED CONTENT}

\section{Supporting Information}

The Supporting Information is available free of charge on the ACS Publications website at DOI: 10.1021/acs.organomet.6b00778.

General experimental details, chemical shift comparison in four and five coordinated complexes, fluxional behavior of the $\mathrm{DAD}$ ligand in $(\mathrm{DAD}) \mathrm{PtCl}_{2}(\mathrm{CHA}) 4$, studies on allene dissociation on the (DAD) $\mathrm{PtCl}_{2}(\mathrm{CHA})$ 4 depending on solvent, details on the VT and DNMR line-shape analysis of $\mathrm{P}(\mathrm{y}) \mathrm{PtCl}_{2}$ (TMA) 1, details on experimental setup and analysis of SSTD NMR of the rotational movement and ligand exchange of (Py)$\mathrm{PtCl}_{2}$ (DMA) 2, and ligand exchange of (DAD)$\mathrm{PtCl}_{2}$ (DMA) 3 and (DAD) $\mathrm{PtCl}_{2}(\mathrm{CHA}) 4$ with free allenes, enthalpy-entropy compensation effect in the ligand exchange process of complexes 2, 3, and 4, NMR spectra of Pt-allene complexes, and X-ray analysis of complexes 1 and $\mathbf{2}$ (PDF)

Crystallographic data for complexes 1 and $\mathbf{2}$ (CIF) Chemical structure for complexes $\mathbf{1}$ and $\mathbf{2}$ (XYZ) 


\section{AUTHOR INFORMATION}

\section{Corresponding Author}

*E-mail: m.munoz-herranz@uea.ac.uk.

ORCID ${ }^{\circ}$

María Paz Muñoz: 0000-0001-9037-349X

\section{Author Contributions}

"These authors contributed equally.

\section{Notes}

The authors declare no competing financial interest.

\section{ACKNOWLEDGMENTS}

Funding by the University of East Anglia, the EPSRC (EP/ L012855/1), and the EU (H2020-MSCA-IF-2014-EF-ST658172) is gratefully acknowledged (M.T.Q.). The authors thank Dr. C. J. Macdonald, NMR manager of the School of Chemistry at UEA, for his help with the NMR experiments. We thank the EPSRC UK National Crystallography Service at the University of Southampton for the collection of the crystallographic data. The authors thank the EPSRC National Mass Spectrometry Service Centre, Swansea, for MS analysis.

\section{REFERENCES}

(1) For selected reviews on transition-metal-catalyzed reactions of allenes, see: (a) Hashmi, A. S. K. Angew. Chem., Int. Ed. 2000, 39, 3590-3593. (b) Zimmer, R.; Dinesh, C. U.; Nandanan, E.; Khan, F. A. Chem. Rev. 2000, 100, 3067-3125. (c) Alcaide, B.; Almendros, P.; Martínez del Campo, M. T. Chem. - Eur. J. 2010, 16, 5836-5842. (d) López, M.; Mascareñas, J. L. Chem. - Eur. J. 2011, 17, 418-428. (e) Aubert, C.; Fensterbank, L.; Garcia, P.; Malacria, M.; Simonneau, A. Chem. Rev. 2011, 111, 1954-1993. (f) Krause, N.; Winter, C. Chem. Rev. 2011, 111, 1994-2009. (g) Yu, S.; Ma, S. Angew. Chem., Int. Ed. 2012, 51, 3074-3112. (h) Themed issue: Progress in Allene Chemistry (guest editors B. Alcaide and P. Almendros) Chem. Soc. Rev. 2014, 43, 2879-3206. For a review on insertion reactions of allenes with transition-metal complexes, see: (i) Bai, T.; Ma, S.; Jia, G. Coord. Chem. Rev. 2009, 253, 423-448.

(2) For selected reviews on metal-allene complexes, see: Bowden, F. L.; Giles, R. Coord. Chem. Rev. 1976, 20, 81-106. (b) Shaw, B. L.; Stringer, A. J. Inorg. Chim. Acta, Rev. 1973, 7, 1-10. For a review on gold- $\eta^{2}$-coordination to unsaturated compounds, see: (c) Schmidbaur, H.; Schier, A. Organometallics 2010, 29, 2-23. For computational studies on metal-allene complexes: (d) Yang, W.; Hashmi, S. A. K. Chem. Soc. Rev. 2014, 43, 2941-2955. (e) Soriano, E.; Fernández, I. Chem. Soc. Rev. 2014, 43, 3041-3105.

(3) For studies on coordination of gold to the central carbon of allenes, see: (a) Chenier, J. H. B.; Howard, J. A.; Mile, B. J. Am. Chem. Soc. 1985, 107, 4190-4191. (b) Gandon, V.; Lemière, G.; Hours, A.; Fensterbank, L.; Malacria, M. Angew. Chem., Int. Ed. 2008, 47, 75347538. (c) Dyker, C. A.; Lavallo, V.; Donnadieu, B.; Bertrand, G. Angew. Chem., Int. Ed. 2008, 47, 3206-3209. (d) Kaufhold, O.; Hahn, F. E. Angew. Chem., Int. Ed. 2008, 47, 4057-4061. (e) Fürstner, A.; Alcarazo, M.; Goddard, R.; Lehmann, C. W. Angew. Chem., Int. Ed. 2008, 47, 3210-3214. (f) Esterhuysen, C.; Frenking, G. Chem. - Eur. J. 2011, 17, 9944-9956.

(4) For selected examples, see: (a) Hashmi, A. S. K.; Kurpejović, E.; Frey, W.; Bats, J. W. Tetrahedron 2007, 63, 5879-5885. (b) Zhang, G.; Catalano, V. J.; Zhang, L. J. Am. Chem. Soc. 2007, 129, 11358-11359.

(c) Computational Mechanisms of $A u$ and Pt Catalyzed Reactions; Soriano, E., Marco-Contelles, J. M., Eds.; Topics in Current Chemistry 302; Spriger: Heidleberg, 2011. The first gold-catalyzed reactions of allenes were reported in 2000; see: Hashmi, A. S. K.; Schwarz, L.; Choi, J. H.; Frost, T. M. Angew. Chem., Int. Ed. 2000, 39, 2285-2288. (5) (a) Muñoz, M. P.; de la Torre, M. C.; Sierra, M. A. Adv. Synth. Catal. 2010, 352, 2189-2194. (b) Muñoz, M. P.; de la Torre, M. C.; Sierra, M. A. Chem. - Eur. J. 2012, 18, 4499-4504.
(6) For selected reviews on metal-catalyzed hydroalkoxylation of allenes, see: (a) Muñoz, M. P. Org. Biomol. Chem. 2012, 10, 35843594 and references therein. (b) Muñoz, M. P. Chem. Soc. Rev. 2014, 43, 3164-3183. For selected examples on Au-catalyzed hydroalkoxylation of allenes, see: (c) Hoffmann-Roder, A.; Krause, N. Org. Lett. 2001, 3, 2537-2538. (d) Nishina, N.; Yamamoto, Y. Tetrahedron Lett. 2008, 49, 4908-4911. (e) Zhang, Z.; Widenhoefer, R. A. Org. Lett. 2008, 10, 2079-2081. (f) Zhang, Z.; Lee, S. D.; Fisher, A. S.; Widenhoefer, R. A. Tetrahedron 2009, 65, 1794-1798. (g) Nishina, N.; Yamamoto, Y. Tetrahedron 2009, 65, 1799-1808. (h) Cui, D.-M.; Yu, K. R.; Zhang, C. Synlett 2009, 2009, 1103-1106. (i) Cui, D.-M.; Zheng, Z.-L.; Zhang, C. J. Org. Chem. 2009, 74, 1426-1427. (j) Paton, R. S.; Maseras, F. Org. Lett. 2009, 11, 2237-2240. (k) Hadfield, M. S.; Lee, A.-L. Org. Lett. 2010, 12, 484-487. For selected examples on Aucatalyzed indolylation of allenes, see: (1) Zhang, Z.; Liu, C.; Kinder, R E.; Han, X.; Qian, H.; Widenhoefer, R. A. J. Am. Chem. Soc. 2006, 128, 9066-9073. (m) Liu, C.; Widenhoefer, R. A. Org. Lett. 2007, 9, 19351938. (n) Widenhoefer, R. A. Chem. - Eur. J. 2008, 14, 5382-5391. (o) Shen, H. C. Tetrahedron 2008, 64, 3885-3903.

(7) So far, a fully relativistic comparison of gold and platinum catalysis has only been conducted for the activation of alkynes by these metals: Pernpointner, M.; Hashmi, A. S. J. Chem. Theory Comput. 2009, 5, 2717-2725. In this context, also the computational study of $\sigma$ - versus $\pi$-allyl complexes must be noted: Hashmi, A. S.; Schuster, A. M.; Litters, S.; Rominger, F.; Pernpointner, M. Chem. - Eur. J. 2011, $17,5661-5667$.

(8) Phosphine-Pt-allene complexes are unstable and show slow dissociation of the allene in solution, with slow fluxional behavior. For selected examples, see: (a) Yasuoka, N.; Morita, M.; Kai, Y.; Kasai, N. J. Organomet. Chem. 1975, 90, 111-121. (b) Briggs, J. R.; Crocker, C.; McDonald, W. S.; Shaw, B. L. J. Chem. Soc., Dalton Trans. 1981, 121125. As phosphine-Pt complexes are not active catalysts in our reactions, we did not include them in this study.

(9) For selected examples of other Pt-allene complexes, see: (a) Osborn, J. A. Chem. Commun. 1968, 1231-1232. (b) Yasuoka, N.; Morita, M.; Kai, Y.; Kasai, N. J. Organomet. Chem. 1975, 90, 111121. (c) Hewitt, T. G.; de Boer, J. J. J. Chem. Soc. A 1971, 817-822. (d) Lentz, D.; Nickelt, N.; Willemsen, S. Chem. - Eur. J. 2002, 8, 1205-1217.

(10) We have tested some of the complexes in our dihydroxylation reaction, and they have shown catalytic activity. For example, reaction of cyclohexylallene with 1,2-propandiol in the presence of catalytic $\mathrm{DADPtCl}_{2}(\mathrm{DAD}=t \mathrm{Bu}-\mathrm{N}=\mathrm{CH}-\mathrm{CH}=\mathrm{N}-\mathrm{Bu})(5 \mathrm{~mol} \%) / \mathrm{AgNTf}_{2}$ (10 mol\%) gave the cyclic acetal in $66 \%$ when the reaction was carried

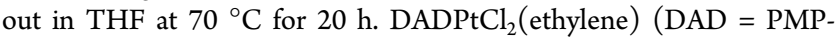
$\mathrm{N}=\mathrm{CH}-\mathrm{CH}=\mathrm{N}-\mathrm{PMP}$ ) gave the cyclic acetal in $96 \%$ in $7 \mathrm{~h}$, and a similar result was obtained with that complex and $\operatorname{AgNTf}_{2}$. $\mathrm{PyPtCl}_{2}$ (ethylene) gave the cyclic acetal in $60 \%$ in $30 \mathrm{~h}$. Besides, the preformed complex 4 also acts as catalyst in the reaction of allenes with alcohols as nucleophiles. These results and the full mechanistic study of this reaction will be reported in detail in due course.

(11) SSTD NMR method: (a) Quirós, M. T.; Angulo, J.; Muñoz, M. P. Chem. Commun. 2015, 51, 10222-10225. (b) Quirós, M. T.; MacDonald, C.; Angulo, J.; Muñoz, M. P. J. Visualized Exp. 2016, 117, e54499.

(12) For an example of intra- vs intermolecular pathways in the fluxional behavior of platinum $(0)$ complexes, see: Zenkina, $\mathrm{O}$. V.; Konstantinovski, L.; Freeman, D.; Shimon, L. J. W.; van der Boom, M. E. Inorg. Chem. 2008, 47 (9), 3815-3822.

(13) (a) Bongers, N.; Krause, N. Angew. Chem., Int. Ed. 2008, 47, 2178-2181. (b) Alonso, J. M.; Quirós, M. T.; Muñoz, M. P. Org. Chem. Front. 2016, 3, 1186-1204.

(14) (a) Forsen, S.; Hoffman, R. A. Acta Chem. Scand. 1963, 17, 1787-1788. (b) Forsen, S.; Hoffman, R. A. J. Chem. Phys. 1963, 39, $2892-2901$.

(15) Mayer, M.; Meyer, B. Angew. Chem., Int. Ed. 1999, 38, 17841788. 
(16) (a) Orchin, M.; Schmidt, P. J. Inorg. Chim. Acta, Rev. 1968, 2, 123-135. (b) Rowe, M. P.; Steinecker, W. H.; Zellers, E. T. Anal. Chem. 2007, 79, 1164-1172.

(17) For examples of five- vs four-coordination in olefin-Pt- $N, N$ bidentate ligands complexes, see: (a) Maresca, L.; Natile, G.; Calligaris, M.; Delise, P.; Randaccio, L. J. Chem. Soc., Dalton Trans. 1976, 23862390. (b) van der Poel, H.; van Koten, G. Inorg. Chem. 1981, 20, 2941-2950. (c) Albano, V. G.; Demartin, F.; de Renzi, A.; Morelli, G.; Saporito, A. Inorg. Chem. 1985, 24, 2032-2039. (d) de Felice, V.; Giordano, F.; Orabona, I.; Tesauro, D.; Vitagliano, A. J. Organomet. Chem. 2001, 622, 242-250.

(18) For selected examples of Pt-olefin complexes, see: (a) Cope, A. C.; Ganellin, C. R.; Johnson, H. W., Jr.; van Auken, T. V.; Winkler, H. J. J. Am. Chem. Soc. 1963, 85, 3276-3279. (b) Foulds, G. A.; Thornton, D. A.; Watkins, G. M. Spectrochim. Acta 1992, 48A, 577595. (c) Hoyte, S. A.; Spencer, J. L. Organometallics 2011, 30, 54155423. For a review on Pt- $\mathrm{C}=\mathrm{C}$ complexes, see: (d) Forniés, J.; Lalinde, E. Platinum-Carbon $\pi$-Bonded Complexes; Michael, D., Mingos, P., Crabtree, R. H., Eds.; Comprehensive Organometallic Chemistry III; Elsevier: Oxford, 2007; Vol. 8.09, pp 611-673.

(19) (a) Vrieze, K.; Volger, H. C.; Gronert, M.; Praat, A. P. J. Organomet. Chem. 1969, 16, P19-P22. (b) Vrieze, K.; Volger, M.; Praat, A. P. J. Organomet. Chem. 1970, 21, 467-475.

(20) Coles, S. J.; Gale, P. A. Chem. Sci. 2012, 3, 683-689.

(21) Malacria et al. have reported DFT calculations showing that $\eta^{1}$ $\mathrm{Pt}(\mathrm{II})$-allene complexes adopt a bent conformation with $\mathrm{C}=\mathrm{C}=\mathrm{C}$ angles of $129-140^{\circ}$. See ref $3 b$.

(22) For selected examples of proposed $\eta^{1}$-Pt-allene as intermediates or transition states, see: (a) Funami, H.; Kusama, H.; Iwasawa, N. Angew. Chem., Int. Ed. 2007, 46, 909-911. (b) Trillo, B.; López, M.; Gulías, M.; Castedo, L.; Mascareñas, J. L. Angew. Chem., Int. Ed. 2008, 47, 951-954.

(23) Interestingly, this effect is opposite in Au-allene complexes as reported by Widenhoefer: (a) Brown, T. J.; Sugie, A.; Dickens, M. G.; Widenhoefer, R. A. Organometallics 2010, 29, 4207-4209. (b) Brown, T. J.; Sugie, A.; Leed, M. G. D.; Widenhoefer, R. A. Chem. - Eur. J. 2012, 18, 6959-6971.

(24) Crociani, B.; Di Bianca, F.; Bertani, R.; Zanotto, L. Inorg. Chim. Acta 1988, 141, 253-261.

(25) Gutmann, V. Coord. Chem. Rev. 1976, 18, 225-255 and references therein.

(26) For studies on dynamic behavior on Au-allene complexes, see ref 23. For a review on gold catalysis in solution, see: (a) Zhdanko, A.; Ströbele, M.; Maier, M. E. Chem. - Eur. J. 2012, 18, 14732-14744. For the mechanism of racemization of allenes by gold complexes, see: (b) Harris, R. J.; Nakafuku, K.; Widenhoefer, R. A. Chem. - Eur. J. 2014, 20, 12245-12254. (c) Li, H.; Harris, R. J.; Nakafuku, K.; Widenhoefer, R. A. Organometallics 2016, 35, 2242-2248. For selected examples of the fluxional behavior of a Fe-allene complex, see: (d) Oon, S. M.; Jones, W. M. Organometallics 1988, 7, 2172-2177. (e) Manganiello, F. J.; Oon, S. M.; Radcliffe, M. D.; Jones, W. M. Organometallics 1985, 4, 1069-1072.

(27) (a) Cope, A. C.; Moore, W. R.; Bach, R. D.; Winkler, H. J. S. J. Am. Chem. Soc. 1970, 92, 1243-1247. (b) Winchester, W. R.; Jones, W. M. Organometallics 1985, 4, 2228-2230. (c) Lu, Z.; Jones, W. M.; Winchester, W. R. Organometallics 1993, 12, 1344-1350. (d) Klosin, J.; Zheng, X.; Jones, W. M. Organometallics 1996, 15, 3788-3790.

(e) Klosin, J.; Abboud, K. A.; Jones, W. M. Organometallics 1996, 15, 596-603.

(28) For a selected example of Py-Pt-olefin complexes, see: Rowe, M. P.; Steinecker, W. H.; Zellers, E. T. Anal. Chem. 2007, 79, 1164-1172.

(29) TopSpin 3.0 program; Bruker Corp., 2015. http://www.bruker. com/products/mr/nmr/nmr-software/software/topspin/.

(30) We choose TCE for our experiments to compare our results with the previously reported in chloroform but with the flexibility of higher temperature range for the studies with complex $\mathbf{2}$. Both solvents are considered noncoordinating $(\mathrm{DN} \sim 0)$, so no interactions with the solvent are expected in any case.
(31) It is interesting to note the faster $\pi$-face exchange shown by the analogous (IPr)AuTMA complex $\left(\Delta G^{\ddagger}(214 \mathrm{~K})=9.5 \mathrm{kcal} \mathrm{mol}^{-1}\right)$, calculated by Widenhoefer et al. (ref 23) by line-shape analysis of the ${ }^{13} \mathrm{C}$ NMR spectrum of the complex at different temperatures.

(32) Foxman, B.; Marten, D.; Rosan, A.; Raghu, S.; Rosenblum, M. J. Am. Chem. Soc. 1977, 99, 2160-2165.

(33) At this point, we cannot fully rule out the participation of $\eta^{1}$-allyl cations in these processes.

(34) It is worth noting here that temperatures for the study of the rotational movement in this complex were from 337 to $349 \mathrm{~K}$.

(35) (a) Howell, J. A. S.; Burkinshaw, P. M. Chem. Rev. 1983, 83, 557-599. (b) Hatrwig, J. Organotransition Metal Chemistry: From Bonding to Catalysis; University Science Books: Sausalito, CA, 2010; Chapters 5.3 and 5.4, pp 223-247.

(36) Interestingly, the gold complex with the same allene displays an associative mechanism with a two-term rate law with nonzero intercept, suggesting competition between the allene and solvent complexation in the associative mechanism. See ref 23b. However, our $k_{\mathrm{obs}}$ are much slower than the observed for the associative mechanism in the gold-allene complexes, supporting the dissociative mechanism in the Pt-allene complexes.

(37) (a) Herrick, R. S.; Leazer, D. M.; Templeton, J. L. Organometallics 1983, 2, 834-840. (b) Wendt, O. F.; Deeth, R. J.; Elding, L. I. Inorg. Chem. 2000, 39, 5271-5276. (c) Hatrwig, J. Organotransition Metal Chemistry: From Bonding to Catalysis; University Science Books: Sausalito, CA, 2010; Chapters 5.3 and 5.4, pp 230-231.

(38) (a) Leffler, J. E. J. Org. Chem. 1955, 20, 1202-1231. (b) Petersen, R. C. J. Org. Chem. 1964, 29, 3133-3135. (c) McGregor, R.; Milicevic, B. Nature 1966, 211, 523-525. (d) Exner, O. Nature 1970, 227, 366-367. (e) Krug, R. R.; Hunter, W. G.; Grieger, R. A. J. Phys. Chem. 1976, 80, 2335-2340. (f) Krug, R. R.; Hunter, W. G.; Grieger, R. A. J. Phys. Chem. 1976, 80, 2341-2351. (g) Liu, L.; Guo, Q.-X. Chem. Rev. 2001, 101, 673-695. (h) Bunten, K. A.; Poë, A. New J. Chem. 2006, 30, 1638-1649.

(39) HRMS of the new complexes could not be obtained due to decomposition. Complex 4 and its precursor with ethylene were analyzed at the EPSRC National Mass Spectrometry Service Centre (Swansea) by APCI(ASAP) and also solvated in DCM and diluted into $\mathrm{MeOH}$ with $\mathrm{NH}_{4} \mathrm{OAc}$ prior to analysis by data of positive nanospray. A number of ions that suggested the presence of $\mathrm{Pt}$ and $\mathrm{Cl}$, and fragments from the loss of $\mathrm{Cl}$ and $\mathrm{N}$-ligand were identified but could not be fully assigned.

(40) For a more detailed explanation on how to use the DNMR lineshape analysis tool of the TopSpin program, consult the user manual. 